\title{
Does precipitation susceptibility vary with increasing cloud thickness in marine stratocumulus?
}

\author{
C. R. Terai ${ }^{1}$, R. Wood ${ }^{1}$, D. C. Leon ${ }^{2}$, and P. Zuidema ${ }^{3}$ \\ ${ }^{1}$ Department of Atmospheric Sciences, University of Washington, Seattle, Washington, USA \\ ${ }^{2}$ Department of Atmospheric Sciences, University of Wyoming, Laramie, Wyoming, USA \\ ${ }^{3}$ Rosenstiel School of Marine and Atmospheric Sciences, University of Miami, Miami, Florida, USA
}

Correspondence to: C. R. Terai (terai@atmos.washington.edu)

Received: 29 November 2011 - Published in Atmos. Chem. Phys. Discuss.: 19 December 2011

Revised: 13 April 2012 - Accepted: 7 May 2012 - Published: 24 May 2012

\begin{abstract}
The relationship between precipitation rate and accumulation mode aerosol concentration in marine stratocumulus-topped boundary layers is investigated by applying the precipitation susceptibility metric to aircraft data obtained during the VOCALS Regional Experiment. A new method to calculate the precipitation susceptibility that incorporates non-precipitating clouds is introduced. The mean precipitation rate $R$ over a segment of the data is expressed as the product of a drizzle fraction $f$ and a drizzle intensity $I$ (mean rate for drizzling columns). The susceptibility $S_{x}$ is then defined as the fractional decrease in precipitation variable $x=\{R, f, I\}$ per fractional increase in the concentration of aerosols with dry diameter $>0.1 \mu \mathrm{m}$, with cloud thickness $h$ held fixed. The precipitation susceptibility $S_{\mathrm{R}}$ is calculated using data from both precipitating and nonprecipitating cloudy columns to quantify how aerosol concentrations affect the mean precipitation rate of all clouds of a given $h$ range and not just the mean precipitation of clouds that are precipitating. $S_{\mathrm{R}}$ systematically decreases with increasing $h$, and this is largely because $S_{\mathrm{f}}$ decreases with $h$ while $S_{\mathrm{I}}$ is approximately independent of $h$. In a general sense, $S_{\mathrm{f}}$ can be thought of as the effect of aerosols on the probability of precipitation, while $S_{\mathrm{I}}$ can be thought of as the effect of aerosols on the intensity of precipitation. Since thicker clouds are likely to precipitate regardless of ambient aerosol concentration, we expect $S_{\mathrm{f}}$ to decrease with increasing $h$. The results are broadly insensitive to the choice of horizontal averaging scale. Similar susceptibilities are found for both cloud base and near-surface drizzle rates. The analysis is repeated with cloud liquid water path held fixed instead of cloud thickness. Simple power law relationships relating
\end{abstract}

precipitation rate to aerosol concentration or cloud droplet concentration do not capture this observed behavior.

\section{Introduction}

Drizzle with wide ranging intensities and areal extent is a common feature in stratocumulus-topped boundary layers, especially in remote marine environments (Brost et al., 1982; Nicholls and Leighton, 1986; Frisch et al., 1995; Vali et al., 1998; Yuter et al., 2000; Pawlowska and Brenguier, 2003; Bretherton et al., 2004; Comstock et al., 2004; vanZanten et al., 2005; Leon et al., 2008; Kubar et al., 2009). Over parts of the eastern subtropical/tropical oceans dominated by stratocumulus, including the southeastern Pacific, the intensity and frequency of drizzle tends to increase westwards from the coast (Leon et al., 2008; Kubar et al., 2009; Bretherton et al., 2010). The westward increase in drizzle coincides with changes in both aerosol concentrations and macrophysical properties of the stratocumulus deck (e.g., George and Wood, 2010; Bretherton et al., 2010; Allen et al., 2011), thereby raising the question: to what extent does the westward increase in drizzle reflect changes in cloud macrophysical properties, changes in cloud microphysical properties, and changes in aerosol (e.g., Wood et al., 2009)?

Of the drizzle falling from stratocumulus, a significant fraction evaporates before reaching the surface (Comstock et al., 2004; vanZanten et al., 2005; Wood, 2005). Whether evaporating or not, drizzle can substantially change the boundary layer characteristics by vertically redistributing energy and water. Therefore, to improve the simulated 
structural and radiative properties of stratocumulus in general circulation models, we need a better understanding of the macrophysical and microphysical properties that determine the frequency and intensity of drizzle (Wyant et al., 2007).

Aerosol indirect effects (AIEs), broadly defined here as the effect of aerosols on the cloud albedo, are strongly sensitive to the amount of drizzle falling from warm clouds (Rotstayn and Liu, 2005) and to the amount evaporating below cloud (Wood, 2007; Chen et al., 2011). The AIEs have been difficult to quantify, in part because different cloud types respond differently to perturbations in aerosol concentration (Ackerman, 2004; Stevens and Feingold, 2009). A key effect that aerosols can have on clouds is the suppression of warm rain, which forms the basis of the second AIE (Albrecht, 1989). Part of the difficulty in quantifying the magnitude of the second AIE is that warm rain responses to perturbed aerosol concentrations are poorly understood.

Accumulation mode aerosols, which often are good proxies for cloud condensation nuclei (Martin et al., 1994), have a typical size range of 0.1 to $1 \mu \mathrm{m}$ (Seinfeld and Pandis, 2006). In many marine environments where accumulation mode aerosol concentrations are typically $<200 \mathrm{~cm}^{-3}$, increasing the accumulation mode aerosol number concentration increases the cloud droplet number concentration $N_{\mathrm{d}}$ in similar proportion (Ramanathan et al., 2001). In warm clouds, the increase in $N_{\mathrm{d}}$ reduces the average cloud droplet size, reduces the collision coalescence efficiency, and suppresses precipitation formation (Albrecht, 1989, inter alia). This effect of accumulation mode aerosols on precipitation is different from the effect that larger giant cloud condensation nuclei (GCCN) have on the precipitation. Studies of GCCN show that in certain situations, increases in the concentration of GCCN leads to more precipitation (Feingold et al., 1999; L'Ecuyer et al., 2009; Hudson et al., 2011), though the overall impacts remain inconclusive (Gerber and Frick, 2012). However, it has been difficult to assess the extent of this suppression in observational datasets, because aerosol concentrations tend to correlate well with meteorological factors, making it difficult to separate the aerosol effects from simultaneous macrophysical drivers (Mauger and Norris, 2007; George and Wood, 2010).

The precipitation susceptibility metric $S_{0}$ quantifies the suppression of precipitation by aerosols, while minimizing the confounding effects of macrophysics (Feingold and Siebert, 2009). It is defined as

$S_{0}=\left(-\frac{d \ln R}{d \ln N_{\mathrm{d}}}\right)_{\text {macro }}$,

where $R$ represents the precipitation rate (at some altitude) and $N_{\mathrm{d}}$ represents the cloud droplet number concentration (Feingold and Siebert, 2009). The subscript "macro" indicates that the susceptibility is calculated with fixed cloud macrophysical properties, e.g., fixed cloud thickness or liquid water path (LWP). This is critical because significant correlations between the microphysical and meteorological properties could potentially cause non-zero precipitation susceptibility even if the aerosols are not responsible for the precipitation changes. In previous studies that used satellite measurements to estimate the susceptibility, the $N_{\mathrm{d}}$ in Eq. (1) was replaced with a cloud condensation nuclei proxy $\alpha$ (Sorooshian et al., 2009; Duong et al., 2011). In the satellite studies, the aerosol index, which is the product of the aerosol optical depth and the Ångstrom exponent and is an indicator of column integrated CCN concentrations (Sorooshian et al., 2009; Duong et al., 2011), was used in place of $\alpha$. This study uses the ambient accumulation mode aerosol concentration to obtain susceptibility estimates in place of $\alpha$ to calculate the susceptibility.

Precipitation susceptibility estimates for marine stratocumulus can be obtained from previous field studies. Field studies of precipitating stratocumulus (e.g., Pawlowska and Brenguier, 2003; Comstock et al., 2004; vanZanten et al., 2005) identified that simple power law relationships display some skill in relating the cloud base precipitation rate $R_{\mathrm{CB}}$ to cloud thickness $h$ (or, alternatively, LWP) and to cloud droplet number concentration $N_{\mathrm{d}}$ (Geoffroy et al., 2008). The relationships take the form

$R_{\mathrm{CB}}=A h^{\gamma} N_{\mathrm{d}}{ }^{-\beta}$.

For clouds with the same thickness $h$, the exponent $\beta$ is identical to the susceptibility $S_{0}$ in Eq. (1). The $\beta$ values reported in previous field studies range from 1 to 1.75 (Geoffroy et al., 2008). Variations in $\beta$ with cloud thickness, however, have not been reported in these studies. This may be primarily due to sampling constraints in the previous studies, but it is important to point out that in fitting a single power law to the data, one implicitly assumes that the precipitation susceptibility does not vary with cloud thickness. Recent satellite observations (Kubar et al., 2009) and simple theoretical model results (Wood et al., 2009) provide observational evidence and theoretical justification that the precipitation susceptibility decreases as the cloud thickness increases in marine stratocumulus. Studies of warm cumulus clouds (Sorooshian et al., 2010; Duong et al., 2011), on the other hand, report that the susceptibility peaks at intermediate values of cloud LWP $\left(\sim 600-1300 \mathrm{~g} \mathrm{~m}^{-2}\right)$. Reconciling these various relationships into a coherent framework to explain precipitation susceptibility in warm clouds is likely to be a formidable challenge.

In this study we investigate the factors controlling precipitation susceptibility in warm, stratiform clouds using aircraft observations of precipitating and non-precipitating marine stratocumulus observed in the southeastern Pacific during the VOCALS Regional Experiment (REx, Wood et al., 2011b). The susceptibility metric is used to determine the extent to which precipitation susceptibility depends upon cloud thickness/LWP. The manuscript is organized as follows. Section 2 describes the data used in the analysis and the methods used to calculate the susceptibilities. Section 3 reports the susceptibilities that are calculated and their associated sensitivities to the averaging length, to the height of the drizzle, and to 
the different methods of calculating the susceptibility. How the results fit in with the existing literature and the precautions that need to be taken when interpreting the susceptibility metric are discussed in Sect. 4. In Appendix A, susceptibilities are calculated on synthetic datasets with a prescribed dependence of $R$ on $N$ to compare the method that we use in this study, tercile log-differencing (TLD), with other methods that can also be used to estimate the susceptibility.

\section{Data and methods}

We use a combination of in-situ and remotely sensed observations of aerosol and cloud properties from eleven research flights of the NSF/NCAR C-130 aircraft during VOCALS REx, which was conducted in the southeast Pacific during October and November 2008 (Wood et al., 2011b). Since aerosol measurements are missing from RF03 and cloud thickness measurements are missing from RF01 and RF09, data from only eleven of the total fourteen research flights are used. The data used in this study are all analyzed at $1 \mathrm{~Hz}$ time resolution, which translates to a spatial resolution of approximately $100 \mathrm{~m}$.

\subsection{Cloud macrophysical properties}

Cloud macrophysical properties (thickness and LWP), drizzle properties (rates at cloud base and below cloud), and aerosol properties below cloud are obtained simultaneously from straight and level flight legs flown below the cloud at approximately $150 \mathrm{~m}$ altitude (subcloud legs). Cloud thickness, precipitation rate, and cloud LWP are estimated from measurements obtained from the Wyoming Cloud Lidar (WCL), the Wyoming Cloud Radar (WCR), and the G-band Vapor Radiometer (GVR). The cloud base height is determined from the column maximum vertical gradient in the lidar backscatter. The cloud top height is determined from the maximum height at which the power return and the variance of the WCR Doppler velocity exceed threshold values. An overview of cloud properties observed during VOCALS REx can be found in Bretherton et al. (2010). Details of the LWP retrievals from the GVR can be found in Zuidema et al. (2012). Cloud thicknesses are available from $51 \%$ of all clouds detected with the WCL, because cloud top heights are not retrievable for clouds with low radar reflectivity; cloud thicknesses are available from $80 \%$ of samples in which the column maximum reflectivity exceeds $-20 \mathrm{dBZ}$. On the other hand, the cloud LWP measurements are available from the GVR for $69 \%$ of all clouds and $86 \%$ of clouds with maximum reflectivity greater than $-20 \mathrm{dBZ}$. If cloud thickness or LWP retrievals are missing over portions of a flight segment, those portions are not included in the calculation of segment averaged precipitation rate $R$ or other precipitation variables, i.e. $f$ and $I$.

\subsection{Precipitation rate estimates}

Unless otherwise noted, precipitation rates $R$ are obtained from radar reflectivities $Z$ at cloud base using the $Z-R$ relationship $R\left(\mathrm{~mm} \mathrm{day}^{-1}\right)=2.01 Z^{0.77}$, proposed by Comstock et al. (2004). A reflectivity threshold of $-15 \mathrm{dBZ}$, corresponding to a drizzle rate of $0.14 \mathrm{~mm} \mathrm{day}^{-1}$, is used to distinguish between drizzling and non-drizzling clouds. Cloud base precipitation rates are used, because this is the most energetically-relevant level for stratocumulus drizzle and to facilitate comparison with previous studies of stratocumulus drizzle (Pawlowska and Brenguier, 2003; Comstock et al., 2004; vanZanten et al., 2005; Wood, 2005). Though using different $Z-R$ relationships has little effect on our results, for the precipitation rates at $250 \mathrm{~m}$, we use the $Z-R$ relationship for surface precipitation from Comstock et al. (2004), $R\left(\mathrm{~mm} \mathrm{day}^{-1}\right)=0.61 Z^{0.91}$ (consistent with Bretherton et al., 2010). For the precipitation rate at $500 \mathrm{~m}$, we use the same $Z-R$ relationship used to calculate the cloud base precipitation rate (consistent with Wood et al., 2011a). Different $Z-R$ relationships for cloud base precipitation rates and surface precipitation rates are obtained by Comstock et al. (2004), because subcloud evaporation increases the mean drizzle drop radius with distance below cloud base (see also vanZanten et al., 2005).

\subsection{Aerosols}

Aerosol concentrations in the subcloud layer are obtained from the Passive Cavity Aerosol Spectrometer Probe (PCASP), which measures aerosol number concentrations in the diameter range of $0.1-3 \mu \mathrm{m}$. In the marine boundary layer, this range captures most of the accumulation mode aerosols (Martin et al., 1994; Ramanathan et al., 2001). The relationship between the PCASP aerosol concentration at $150 \mathrm{~m}$ altitude and the cloud droplet concentration, $N_{\mathrm{d}}$, as measured by the Cloud Droplet Probe (CDP, size range of $1-52 \mu \mathrm{m})$ is analyzed using the data from profile legs flown during the research flights. Profile legs are flight legs flown from below $400 \mathrm{~m}$ to above the inversion or vice versa (with a rate of ascent/decent typically around $300 \mathrm{~m} \mathrm{~min}^{-1}$ ). From 90 profiles, we compare mean PCASP aerosol concentrations, $N$, from below $220 \mathrm{~m}$ with mean in-cloud $N_{\mathrm{d}}$ to establish the relationship between them.

\subsection{Averaging scale}

Though we test the sensitivity of the susceptibility estimates to the averaging length, we choose to average the data over $10 \mathrm{~km}$ segments (100 s of data) in the bulk of our analyses, because drizzle has been found to vary at this scale (vanZanten et al., 2005), and the dominant scale of variability in marine stratocumulus clouds is usually that associated with mesoscale cellular structures with scales of this order (Wood and Hartmann, 2006). We find an $e$-folding length of $1.6 \mathrm{~km}$ 
for the cloud base precipitation rate field, suggesting that for the dataset as a whole, the shortest averaging length scale for independent data segments (Leith, 1973) is $3.2 \mathrm{~km}$. Similarly, the $e$-folding length for the cloud thickness is $1.7 \mathrm{~km}$. A given $10 \mathrm{~km}$ segment (100 s of data) from the subcloud leg is used in the analysis if estimates of cloud thickness (or cloud LWP) and aerosol concentration are available for some or for the entire segment. Means of precipitation and cloud thickness are averaged over only the regions of the $10 \mathrm{~km}$ segments where cloud thickness measurements are obtained. Since cloud thickness measurements could not be obtained for the thinnest of clouds, our analysis is restricted to the thicker clouds that were sampled by the research flights.

\subsection{Susceptibility estimation}

The $10 \mathrm{~km}$ segment-averaged cloud thickness $h$, PCASP aerosol concentration $N$, and precipitation rate $R$ are plotted in Fig. 1. Along the $\mathrm{x}$-axis towards thicker clouds, $R$ increases substantially. To a lesser extent, towards higher $N, R$ decreases. The aim of this study is to quantify this decrease in $R$ with increasing $N$.

The high resolution aircraft data also allow us to determine the fraction and intensity of the drizzle in each segment. Segment-mean precipitation rates $R$ from the $10 \mathrm{~km}$ segments are partitioned into the fraction of the cloudy columns that are drizzling $f$, and the mean drizzle rate in those columns, here termed drizzle intensity $I$. This relation can be written as

$R=f I$.

A data point in this study consists of estimates of the mean cloud thickness $h$ (or mean cloud LWP), the mean PCASP concentration $N$, and the three precipitation variables $R, f$, and $I$. In non-drizzling segments, where $R=0$ and $f=0, I$ is considered undefined. Hence, only drizzling segments are used to calculate the susceptibility for $I$. This is to reduce the covariance between the susceptibilities of drizzle fraction and intensity when we calculate the total susceptibility..

We examine the susceptibility for $R, f$, and $I$ separately, referring to these susceptibilities as $S_{\mathrm{R}}, S_{\mathrm{f}}$, and $S_{\mathrm{I}}$ respectively. The susceptibility is derived from the observational dataset for four bins of increasing cloud thickness $h$, each with the same number of data points (percentiles $0-25 \%$, $25-50 \%, 50-75 \%, 75-100 \%$ of $h$ ). The range of $h$ in each of the $h$ bins are 14-207 m, 208-294 m, 294-379 m, and 381$792 \mathrm{~m}$. By dividing the data into four bins and estimating the susceptibility separately for each bin, we (a) minimize the macrophysical effects that can be detrimental to our susceptibility estimates and (b) estimate how the susceptibility changes with $h$. The correlations between $h$ and $N$ within the four bins from thinnest to thickest $h$ are $0.3,0.0,-0.1$, and -0.3 respectively.

In contrast to previous studies (e.g., Jiang et al., 2010; Duong et al., 2011) that examined the drizzle susceptibil-

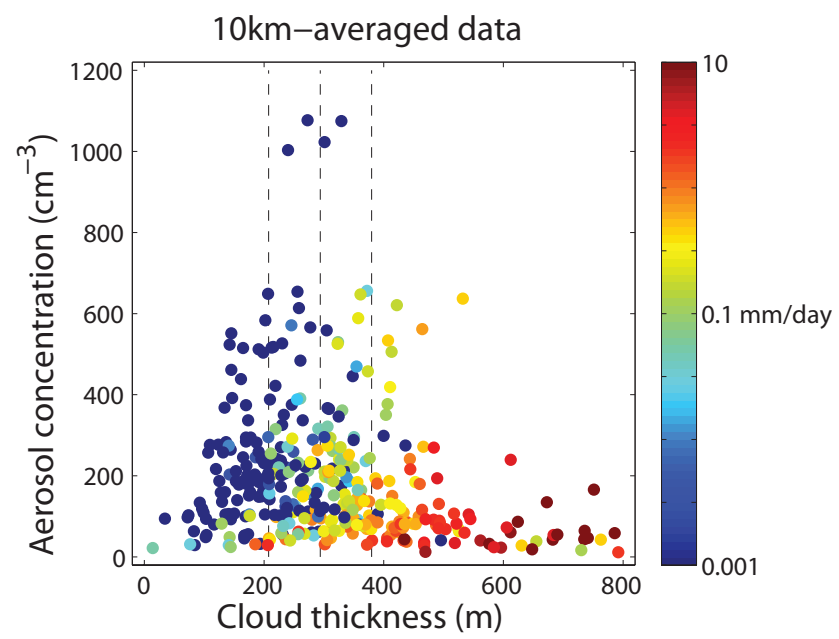

Fig. 1. Distribution of $10 \mathrm{~km}$-averaged aerosol concentration and cloud thickness measurements taken during twelve research flights. Colors indicate cloud base precipitation rates derived from the cloud base reflectivities that were measured by the Wyoming Cloud Radar. Dotted lines indicate the boundaries of the cloud thickness bins described in the text.

ity only in regions determined to be precipitating, using some cutoff to distinguish precipitating and non-precipitating clouds, we examine the drizzle susceptibility of all clouds, precipitating or not, by investigating how aerosols affect both the frequency and the intensity of drizzle in clouds of a given thickness. Thus, this analysis attempts to quantify the effect of aerosols on the mean precipitation rates of all clouds of a given thickness, which is different from quantifying the effect of aerosols on the mean precipitation rates of only precipitating clouds of a given thickness. This approach is appropriate in terms of understanding, because we include clouds for which precipitation is completely suppressed due to high ambient aerosol concentrations. We account for how increased aerosol concentrations can decrease the likelihood that a cloud precipitates, which is important for weaklyprecipitating clouds. By incorporating non-drizzling clouds, we can address two questions in our susceptibility estimates: (a) to what extent do aerosols perturb existing drizzle rates, and (b) to what extent do aerosol perturbations affect the likelihood or fraction of drizzle?

Susceptibilities of each precipitation variable $x=\{R, f, I\}$ are estimated for each of the four cloud thickness bins using the form,

$S_{x}=-\frac{\ln \left(x_{+} / x_{-}\right)}{\ln \left(N_{+} / N_{-}\right)}$,

where the plus and minus subscripts indicate ensemble means of a particular variable over the population corresponding to the top and bottom $33 \%$ of $N$ respectively. We term this approach of calculating the susceptibility tercile log-differencing (TLD). The uncertainty in $S_{x}$ is calculated using bootstrap resampling (Efron and Gong, 1983). For each 
Table 1. Mean values of cloud thickness $h$, PCASP aerosol concentration $N$, and precipitation rate $R$ in the four cloud thickness bins ( $h_{1}, h_{2}, h_{3}, h_{4}$ from bin with thinnest to thickest clouds). Total \# indicates the total number of points ( $10 \mathrm{~km}$ averages) in each bin, and drizzling \# indicates the number of those points where $f>0$. $x_{-}$and $x_{+}$indicate the mean values of $x$ in the population with top and bottom $33 \%$ values of $N$ in each bin.

\begin{tabular}{lcccc}
\hline & $h_{1}$ & $h_{2}$ & $h_{3}$ & $h_{4}$ \\
\hline Total \# & 93 & 93 & 94 & 93 \\
Drizzling \# & 14 & 50 & 80 & 89 \\
mean $R\left(\mathrm{~mm} \mathrm{day}^{-1}\right)$ & 0.04 & 0.12 & 0.30 & 3.69 \\
$\operatorname{mean} h(\mathrm{~m})$ & 153 & 248 & 335 & 505 \\
Min/max $h(\mathrm{~m})$ & $14 / 207$ & $208 / 294$ & $294 / 379$ & $381 / 792$ \\
$N_{-}\left(\mathrm{cm}^{-3}\right)$ & 69 & 85 & 77 & 39 \\
$N_{+}\left(\mathrm{cm}^{-3}\right)$ & 357 & 419 & 411 & 266 \\
$R_{-}\left(\mathrm{mm} \mathrm{day}^{-1}\right)$ & 0.12 & 0.28 & 0.52 & 7.1 \\
$R_{+}\left(\mathrm{mm} \mathrm{day}^{-1}\right)$ & 0.00068 & 0.049 & 0.11 & 1.7 \\
Drizzling \#+ & 10 & 21 & 29 & 30 \\
Drizzling \#+ & 3 & 12 & 23 & 29 \\
\hline
\end{tabular}

cloud thickness bin, the data are resampled with replacement and the resulting susceptibility is calculated 10000 times to obtain a distribution of susceptibility estimates for that cloud thickness bin. The middle 95 th percentile $(2.5 \%, 97.5 \%)$ of this distribution is used to denote the $95 \%$ confidence interval of $S_{x}$. We only report susceptibilities in bins where precipitation is detected in at least $10 \%$ of the segments. We examine the ability of this method to capture the underlying precipitation dependence on aerosol concentration in Appendix A.

Mean properties of $N, h$, and $R$ in the four cloud thickness bins are summarized in Table 1. One of the noticeable changes across the bins is the marked increase in mean $R$. Another is that the range of $N$ observed differs across the bins. Since in the VOCALS region the thickest clouds are found west of $80 \mathrm{~W}$, where aerosol concentrations are typically below $200 \mathrm{~cm}^{-3}$ (Allen et al., 2011), this dataset does not include data points with high aerosol concentrations and high cloud thicknesses.

Wet scavenging of aerosols by precipitation has been inferred by Duong et al. (2011) to negatively bias the susceptibility values that they calculated from satellite measurements. Given the boundary layer conditions that were observed during VOCALS REx, we expect that wet scavenging would have a small effect on our susceptibility estimates, because the time scales for wet scavenging of aerosol are substantially longer than the time scales for drizzle formation and boundary layer mixing. Using the parameterization from Wood (2006) with a cloud base precipitation rate of $1 \mathrm{~mm} \mathrm{day}^{-1}$ and a cloud droplet number concentration of $100 \mathrm{~cm}^{-3}$, we calculate a wet scavenging rate of approximately $3 \mathrm{~cm}^{-3} \mathrm{~h}^{-1}$. Given that the typical lifetime of drizzle cells in the region is approximately two hours (Comstock et al., 2005) and that the mixing of the boundary layer, esti- mated from the convective velocity and depth of the boundary layer, is approximately one hour, we do not expect the aerosol concentrations to decrease substantially before precipitation rates adjust to the changes in aerosol concentrations. Therefore, we expect that wet scavenging would not statistically bias our susceptibility estimates. In making this argument we assume that the cloud thickness and aerosol concentration are the main controls of precipitation, and we cannot rule out the possibility of another control on precipitation that enhances precipitation and hence leads to an anticorrelation between $N$ and $R$ through cumulative wet scavenging events. However, given the nature of our dataset, we cannot test this issue, and hence, we do not filter the data for potential wet scavenging effects.

\section{Results}

\subsection{Aerosol vs. cloud droplet number concentration}

The physical argument that increased aerosol concentrations leads to reduced precipitation is dependent on the assumption that PCASP aerosol concentrations $N$ at $150 \mathrm{~m}$ correlate well with cloud droplet concentrations $N_{\mathrm{d}}$ in the overlying cloud. To test this assumption, we take $N$ and $N_{\mathrm{d}}$ from the profile legs and plot the data in Fig. 2. Each point represents mean aerosol and cloud droplet concentrations from one profile. The square of the linear correlation $\left(r^{2}\right)$ between $N$ and $N_{\mathrm{d}}$ is 0.74 . As in previous studies (McComiskey and Feingold, 2008; Duong et al., 2011), a power law relationship of the form $N_{\mathrm{d}}=A N^{b}$ is used to characterize the relationship between cloud droplet and aerosol number concentration. The exponent $b$, referred to as $\mathrm{ACI}_{\mathrm{N}}$ in the literature (McComiskey and Feingold, 2008), can be thought of as the cloud droplet concentration susceptibility: the fractional increase in cloud droplet concentration in response to the fractional increase in accumulation mode aerosol concentration.

To obtain the $b$ value, $b$ is increased from 0 to 1.5 in increments of 0.05 and the squared correlation $\left(r^{2}\right)$ of $N_{\mathrm{d}}$ and $N^{b}$ is calculated at each increment. The highest $r^{2}$ value of 0.80 is found for $b=0.55$. The $b$ value that we obtain lies within the range of previously reported values $(0.26-0.85$ from McComiskey and Feingold, 2008). A study in the same marine stratocumulus region in the southeast Pacific that used $N_{\mathrm{d}}$ estimated from MODIS retrievals and $N$ from ship-based measurements of accumulation mode aerosols found a $b$ value of 0.56 (Painemal and Zuidema, 2010). This agreement is surprising, given that this simple relationship only uses aerosol concentrations in a single size range and does not take into account the aerosol size distribution, aerosol hygroscopicity, or incloud supersaturation. The $b$ value will be necessary when comparing the $S_{\mathrm{R}}$ values in this study, which quantify precipitation responses to aerosol, with previously reported $\beta$ values from Eq. (2), which quantify precipitation responses to cloud droplets (as in Sect. 3.2). 


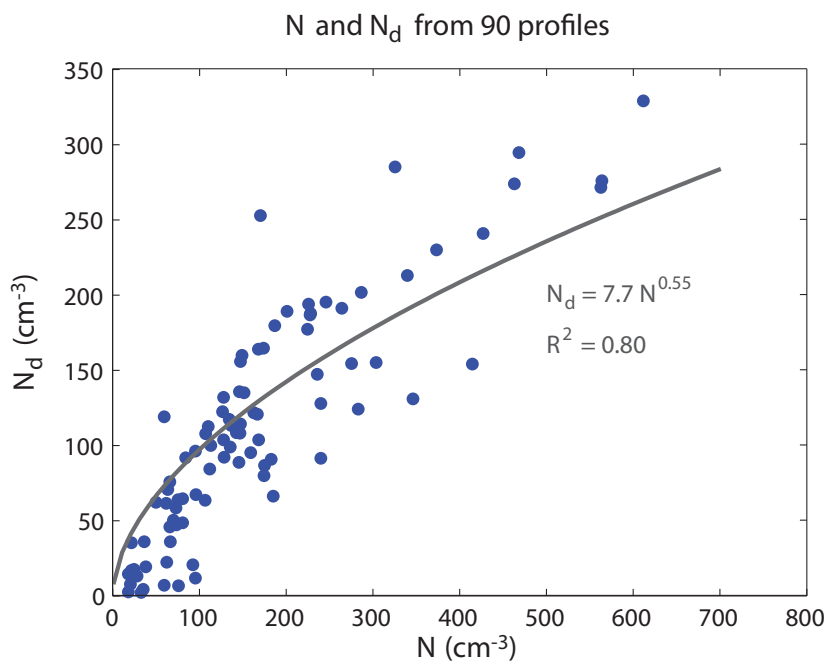

Fig. 2. PCASP measured aerosol concentration $N$ and CDP measured cloud droplet concentration $N_{\mathrm{d}}$ from 90 profiles. $N$ is the mean PCASP concentration at altitudes below $220 \mathrm{~m}$ and $N_{\mathrm{d}}$ is the mean CDP concentration (filtered for incloud). The gray line indicates the line of best fit, determined by the method described in Sect. 3.1.

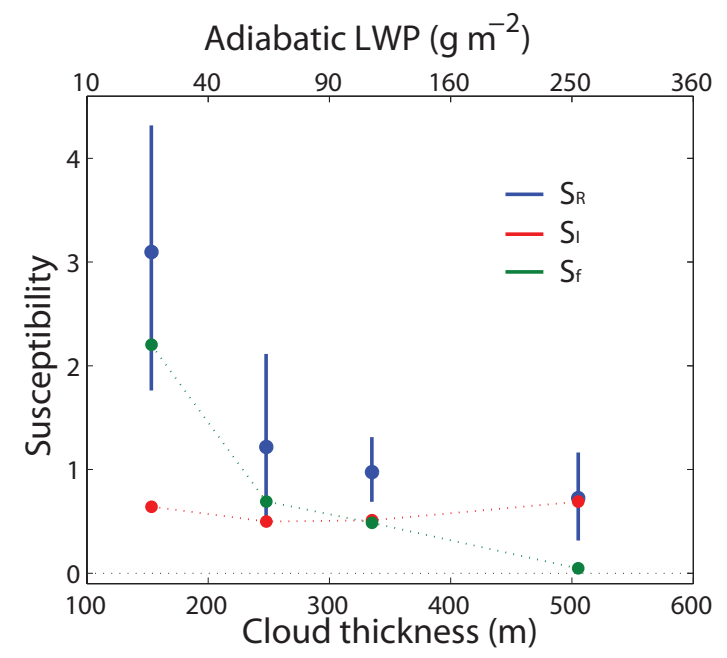

Fig. 3. The precipitation susceptibility (blue), the susceptibility of drizzle intensity (red), and the susceptibility of drizzle fraction (green) are calculated in each of the four equally weighted cloud thickness bins. Error bars on the precipitation susceptibility indicate the $95 \%$ confidence interval calculated using bootstrap resampling technique. The dotted lines exist only to identify points that lie on top of each other. The precipitation susceptibility (blue) is approximately the sum of the susceptibility of drizzle fraction (green) and the susceptibility of drizzle intensity (red). The adiabatic liquid water path axis on the top is estimated from cloud thickness values, using the relationship LWP $=\frac{1}{2} C_{w} h^{2}$, where $C_{w}=2 \times 10^{-6} \mathrm{~kg} \mathrm{~m}^{-4}$ (Pawlowska and Brenguier, 2003).

\subsection{Drizzle susceptibility}

The susceptibility $S_{x}$ of each of the three cloud base precipitation variables $x=\{R, f, I\}$ for each of the cloud thickness bins ( $h$ bins) is shown in Fig. 3. The susceptibility $S_{\mathrm{R}}$ of the mean drizzle rate is clearly positive for all $h$ bins. For each bin there is lower than a $2.5 \%$ chance that $S_{\mathrm{R}}<0$. This is consistent with the hypothesis that increasing aerosols decreases precipitation, as has been noted in numerous previous studies (Pawlowska and Brenguier, 2003; Comstock et al., 2004; vanZanten et al., 2005). The new finding in this study is that $S_{\mathrm{R}}$ decreases strongly with increasing cloud thickness. The $h$-dependence is quite marked, with $S_{\mathrm{R}}$ decreasing monotonically by a factor of four from approximately 3 for the $h$ bin with thinnest clouds (mean $h \approx 150 \mathrm{~m}$ ) to approximately 0.75 for the $h$ bin with the thickest clouds (mean $h \approx 500 \mathrm{~m}$ ).

Further, we find that the susceptibility $S_{\mathrm{f}}$ of drizzle fraction and susceptibility $S_{\mathrm{I}}$ of drizzle intensity exhibit very different dependences upon cloud thickness (Fig. 3). To first order, since $R$ is a product of $f$ and $I, S_{\mathrm{f}}$ and $S_{\mathrm{I}}$ add linearly to give the mean precipitation rate susceptibility, i.e., $S_{\mathrm{R}}=S_{\mathrm{f}}+S_{\mathrm{I}}$. More explicitly, if we expand our susceptibility estimate in Eq. (4), then $S_{\mathrm{R}}$ reduces to the sum between $S_{\mathrm{f}}, S_{\mathrm{I}}$, and a covariance term

$S_{\mathrm{R}}=S_{\mathrm{f}}+S_{\mathrm{I}}-\frac{\ln \left[1+\frac{\overline{I_{+}^{\prime} f_{+}^{\prime}}}{\overline{I_{+}}} \overline{f_{+}}\right]-\ln \left[1+\frac{\overline{I_{-}^{\prime} f_{-}^{\prime}}}{\overline{I_{-}}} \overline{f_{-}}\right]}{\ln \left[N_{+} / N_{-}\right]}$,

where $\overline{I^{\prime} f^{\prime}}$ is the covariance between $I$ and $f$ in each population of $h$ bin. We find that the covariance term is small in our dataset such that we can approximate that $S_{\mathrm{R}} \approx S_{\mathrm{f}}+S_{\mathrm{I}}$.

Like $S_{\mathrm{R}}, S_{\mathrm{f}}$ decreases with increasing $h$ and explains the monotonic decrease in $S_{\mathrm{R}}$ with $h$. Much of this trend can be attributed to the preponderance of non-drizzling segments ( $85 \%$ are non-drizzling) in the bin with thinnest clouds, compared to the near absence of non-drizzling segments ( $4 \%$ are non-drizzling) in the bin with thickest clouds. Aerosols appear, therefore, to have a larger effect in determining the drizzle fraction in thinner clouds, than they do in thicker clouds.

On the other hand, we find that the susceptibility $S_{\mathrm{I}}$ of drizzle intensity does not significantly change with increasing cloud thickness and has a near-constant value $S_{\mathrm{I}} \approx 0.6$. Dividing $S_{\mathrm{R}}$ between the $S_{\mathrm{f}}$ and $S_{\mathrm{I}}$ and comparing their relative contributions demonstrates that drizzle fraction is important to consider when calculating susceptibility in thinner stratocumulus clouds. Finally, we note that the mean $S_{\mathrm{R}}$ of the four $h$ bins is 1.6, which is in the upper part of the range of $\beta$ exponents (Eq. 2) found in previous studies (Geoffroy et al., 2008). We are, however, examining the relationship between ambient aerosol concentration and precipitation, while previous studies examined the relationship between the cloud droplet concentration and precipitation. Based on the $b$ value of 0.55 that we report in Sect. 3.1, we expect that the $S_{R}$ 

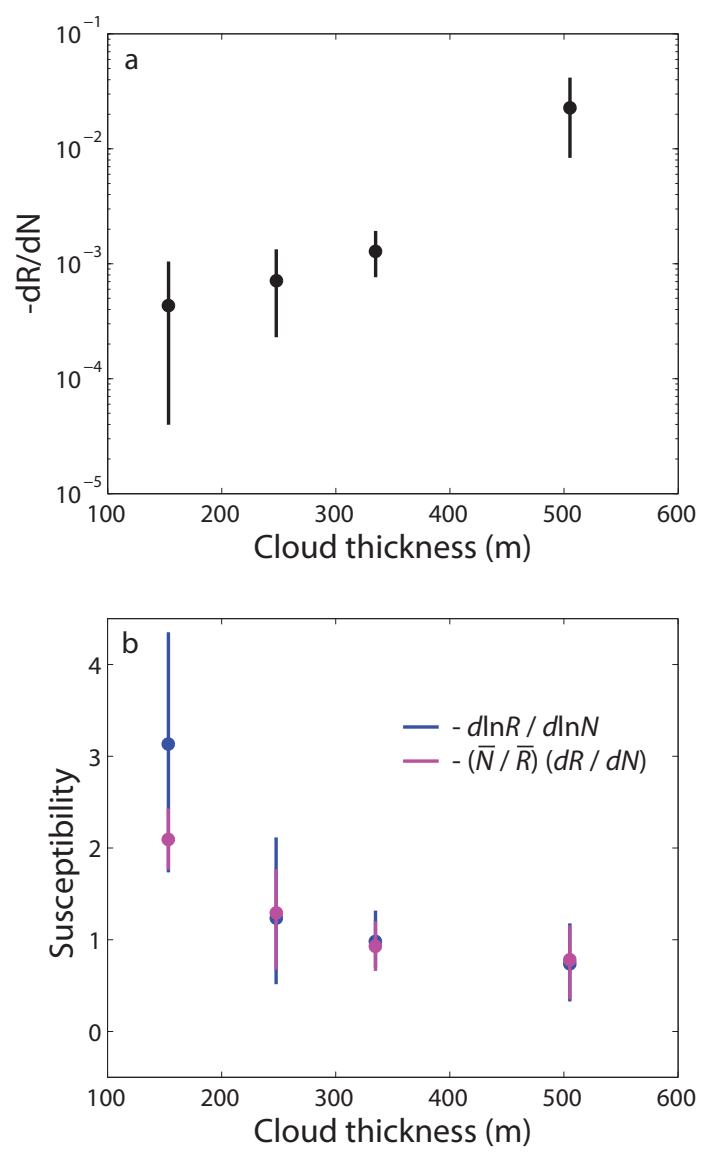

Fig. 4. (a) $-d R / d N$ calculated in the four cloud thickness bins, as described in the Sect. 3.3. (b) The susceptibility calculated using the original formulation of susceptibility (blue) and the susceptibility calculated using the formulation in Eq. (6) (magenta).

would give an underestimate of the relationship between the cloud droplet concentration and precipitation, but we are unable to confirm this from our dataset.

The susceptibility estimates are only useful indicators of the role that aerosols play in modulating precipitation, provided that cloud macrophysical and meteorological properties are held constant. Even when we bin the data by cloud thickness, correlations between macrophysics and microphysics exist. The correlations between $h$ and $N$ in the four cloud thickness bins from thinnest to thickest bin are 0.3 , $0.0,-0.1$, and -0.3 . We argue, however, that the decrease in correlation between $N$ and $h$ with increasing cloud thickness is not the reason why we observe the decrease in $S_{R}$ with increasing cloud thickness in Fig. 3. On the contrary, since there is a strong positive correlation between precipitation and cloud thickness (Pawlowska and Brenguier, 2003; vanZanten et al., 2005), if correlations had a significant effect on the behavior of the susceptibility, we would expect the susceptibility to increase with cloud thickness, instead of decrease with cloud thickness.
To examine whether the behavior of susceptibility is sensitive to the choice of the number of cloud thickness bins, we calculate the susceptibility after binning the data into greater number of bins (up to ten). The susceptibility values do not show a general increase or decrease with increasing number of bins (not shown for cloud thickness). We do observe an increase in the uncertainty (95\% confidence intervals) of the susceptibility estimates, expected due to the increase in sampling error with the reduced number of degrees of freedom per bin. While we observe the same monotonic decrease in susceptibility when we bin the data into five bins, when we bin the data into more bins, a peak in the susceptibility value is found in the second cloud thickness bin from which there is a monotonic decrease in susceptibility with increasing cloud thickness. While there may be a physical explanation for the peak value in the second bin, given the large uncertainty for the susceptibility of the bin with the thinnest clouds in Fig. 3, we cannot establish this with high confidence. The main conclusion that we can make is that the susceptibility value of the thinnest clouds is the least robust to changes in the binning procedure. There is a relatively low number of drizzling clouds, and the inclusion or exclusion of the data points has a large impact on the derived susceptibility.

\section{$3.3-d R / d N$}

While the susceptibility metric provides one way of quantifying the decrease in precipitation $R$ due to an increase in aerosol concentration $N$, we can also calculate the linear change of $R$ due to a change in $N$, i.e., $-d R / d N$, using a similar tercile averaging method of Eq. (4). This may be a more useful metric to quantify the effect of aerosols on precipitation if the interest is in the absolute suppression of precipitation due to an increase in ambient aerosol concentration. In Fig. $4 \mathrm{a}$, we can see that unlike $S_{\mathrm{R}},-d R / d N$ increases with increasing cloud thickness and that the increase is almost fifty fold from the bin with the thinnest clouds to the bin with the thickest clouds. This is the same order of magnitude increase as the increase in mean $R$ across the four bins (see Table 1).

Furthermore, we can estimate the susceptibility $S_{\mathrm{R}}$ from $-d R / d N$ by approximating that

$S_{\mathrm{R}} \approx-\frac{\bar{N}}{\bar{R}} \frac{d R}{d N}$,

where $\bar{R}$ is the bin-mean precipitation rate and $\bar{N}$ is the binmean PCASP aerosol concentration in each $h$ bin. When the initial susceptibility estimate is plotted with this new estimate, the two estimates are consistent with each other within the sampling uncertainty (Fig. 4b). This demonstrates that the susceptibility $S_{\mathrm{R}}$ can be used to estimate both absolute and fractional changes in precipitation in response to increases in $N$. 


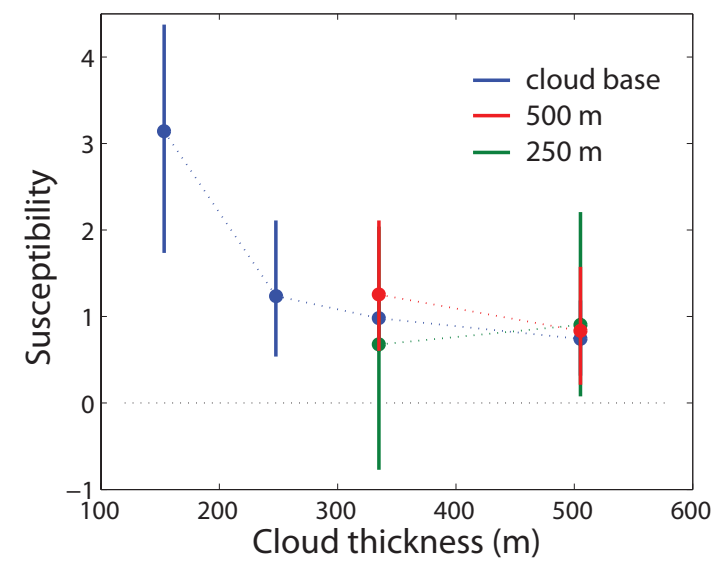

Fig. 5. The precipitation susceptibilities of drizzle at cloud base (blue), at $500 \mathrm{~m}$ (red), and at $250 \mathrm{~m}$ (green) are calculated. Precipitation rates are averaged over $10 \mathrm{~km}$ segments. While the same $Z-R$ relationship ( $Z=0.4 R^{1.3}$ ) from Comstock et al. (2004) is used for cloud base precipitation rates and $500 \mathrm{~m}$ precipitation rates, a different $Z-R$ relationship $\left(Z=1.7 R^{1.1}\right.$ ) is used for the $250 \mathrm{~m}$ precipitation rates.

\subsection{Susceptibility of drizzle at varying heights}

We now examine whether the precipitation susceptibility is sensitive to the altitude at which drizzle is measured (i.e., whether drizzle is measured at cloud base, at the surface, or in an intermediate altitude). Evaporation-sedimentation models and observations have shown that in a number of cases of drizzling marine stratocumulus, much of the drizzle evaporates within $250 \mathrm{~m}$ of the cloud base (Wood, 2005) and that the fraction evaporating by a given level below cloud base is highly sensitive to the mean drizzle drop size. Studies of southeastern Pacific stratocumulus have found that most of the drizzle evaporates before reaching the surface (Comstock et al., 2004; Bretherton et al., 2010). Since the degree of evaporation is important for understanding precipitation impacts on marine stratocumulus (e.g., Wood, 2007; Savic-Jovcic and Stevens, 2008), it is important to establish whether the precipitation susceptibility is markedly different at the surface from that at the cloud base. For example, this might be the case if $N$ were to be strongly correlated with the size of drizzle drops.

We use precipitation rate estimates from the WCR at altitudes of $500 \mathrm{~m}$ and $250 \mathrm{~m}$ (see Sect. 2.2). Radar-derived drizzle rates at the surface are not estimable from the subcloud runs used here, but since the $250 \mathrm{~m}$ altitude is considerably lower than the typical cloud base height of $\sim 1000 \mathrm{~m}$ (Bretherton et al., 2010), the $250 \mathrm{~m}$ level is somewhat representative of conditions near the surface. The susceptibility as a function of height is shown in Fig. 5. Quantitative measures of susceptibility of the precipitation at $500 \mathrm{~m}$ and $250 \mathrm{~m}$ are not obtained in the lower cloud thickness bins, because precipitation is detected in less than $10 \%$ of the segments in

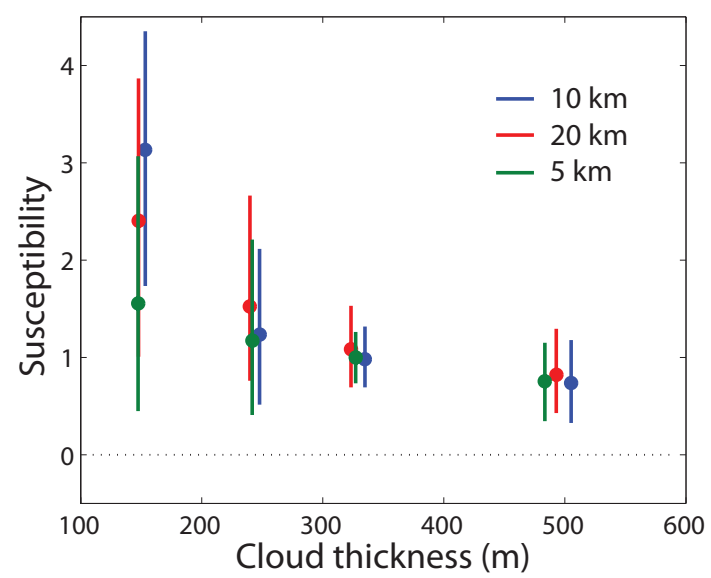

Fig. 6. The precipitation susceptibility are calculated in four equally weighted cloud thickness bins for three different averaging length scales: $10 \mathrm{~km}$ (blue), $20 \mathrm{~km}$ (red), $5 \mathrm{~km}$ (green).

those bins. From Fig. 5, there is no evidence that the susceptibility is a strong function of the height below cloud base. Therefore, use of cloud base vs. surface precipitation rates is unlikely to result in significant changes in the susceptibility estimate. Since we do not have a clear physical justification for why the susceptibility should remain constant with height below cloud base, further studies are needed to establish whether there is indeed a physical explanation for what is observed.

We find that our results are insensitive to the $Z-R$ relationship that is used (see Sect. 2.2). Switching between the two $Z-R$ relationships has less than a $15 \%$ effect on the susceptibility. Since the susceptibility takes the form $-d \ln R / d \ln N$, from the difference in the $Z$ dependence of $R$ alone, we would expect a difference of $18 \%$ in the susceptibility.

\subsection{Susceptibility for different averaging length}

An averaging length of $10 \mathrm{~km}$ is used for the preceding analyses, but now we explore whether different averaging lengths affect the susceptibility estimates. Duong et al. (2011) found that when the averaging area of the LES model output was decreased, the susceptibility maximum shifted to higher LWP values. To address this possible issue in the data, in Fig. 6 we examine the extent to which the precipitation susceptibility is changed by changing the averaging length (i.e., the segment length). The general result that $S_{\mathrm{R}}$ decreases with cloud thickness holds for all different averaging lengths examined here $(5-20 \mathrm{~km})$. The greatest spread is found for the $h$ bin with thinnest clouds, but here the sensitivity to averaging length is not monotonic, so the spread is likely sampling noise. The susceptibility of drizzle fraction $S_{\mathrm{f}}$ contributes to the decreasing trend for all three averaging length scales, while the susceptibility of drizzle intensity $S_{\text {I }}$ also 
remains relatively constant with $h$ for the three averaging length scales and lies between 0.2 and 0.9 .

\subsection{Susceptibility when binned by cloud liquid water path}

So far we have addressed the effect of cloud thickness on the susceptibility. While some studies have examined the effect of cloud thickness on precipitation (Pawlowska and Brenguier, 2003; vanZanten et al., 2005), others have examined cloud liquid water path (LWP) as the macrophysical control of precipitation (Comstock et al., 2004; Sorooshian et al., 2009). The reason for this has been largely driven by the availability of instrumentation. However, in the VOCALS dataset we have estimates of both cloud thickness and LWP. Cloud thickness is typically well correlated with cloud LWP for marine stratocumulus, where the assumption of adiabatic LWP is a good approximation (Albrecht et al., 1990; Zuidema et al., 2005, 2012). In some areas where there is scud (cumulus humulis under stratocumulus), the assumption of adiabatic LWP breaks down. A breakdown is also observed for the thick, strongly precipitating stratocumulus clouds with high values of LWP, although precisely how thick the clouds need to be before this occurs appears to differ between studies and likely depends upon the vigor of the turbulent water resupply (Wood, 2005). This motivates our examination of whether susceptibility trends are different if we bin the data by cloud LWP instead of cloud thickness. The GVR obtained cloud LWP for a greater percentage of clouds (69\%), compared to the WCR and WCL, which obtained cloud thickness values for $51 \%$ of all clouds. Therefore, even if the clouds measured in this region are completely adiabatic, we can expect differences in the susceptibilities from the different sampling.

The susceptibilities estimated when we bin by cloud LWP are shown in Fig. 7. As in previous sections, the LWP data are divided into four bins. However, only three susceptibility estimates are shown for each of the three averaging lengths, because in the bin with the lowest LWP (mean LWP of approximately $15 \mathrm{~g} \mathrm{~m}^{-2}$ ) precipitation is detected in less than $10 \%$ of the segments. The lack of data in the bin with the lowest quartile of LWP value shows again the difficulty in calculating the susceptibility for the thinnest clouds.

Susceptibilities binned by LWP (Fig. 7) are similar to those by cloud thickness (Fig. 6), but the decrease with increasing LWP is not as marked as it is with cloud thickness, and the trend is dependent upon the averaging length. Specifically, when the data are averaged over $5 \mathrm{~km}$ segments, the susceptibility $S_{\mathrm{R}}$ increases from the second to the third LWP bin. This increase in $S_{R}$ from the second to the third LWP bin is due to an increase in $S_{\mathrm{I}}$, which counteracts decreases in $S_{\mathrm{f}}$ from the second to third LWP bin (not shown). Note that $S_{\mathrm{R}}$ from the first bin is not shown for lack of precipitating clouds. $S_{\mathrm{I}}$ also increases from the third to fourth LWP bin, but the decrease in $S_{\mathrm{f}}$ is larger, which leads to the de-

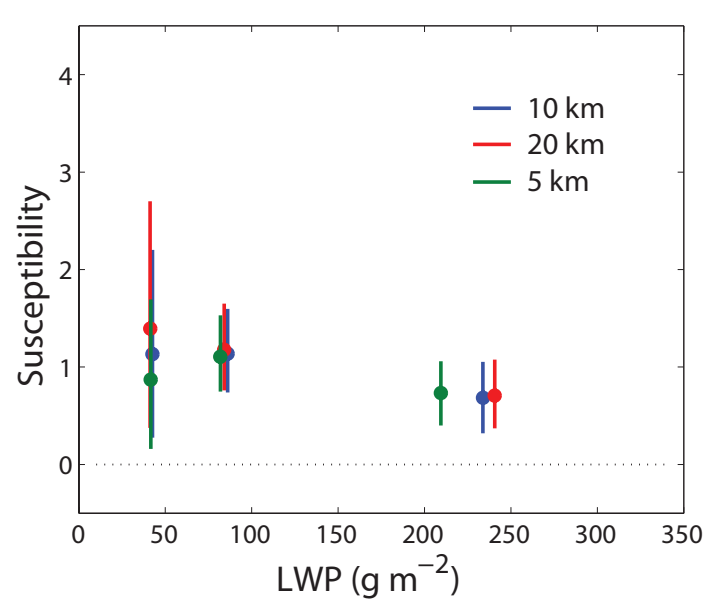

Fig. 7. The precipitation susceptibility is calculated in four equally weighted cloud liquid water path (LWP) bins for three different averaging length scales: $10 \mathrm{~km}$ (blue), $20 \mathrm{~km}$ (red), $5 \mathrm{~km}$ (green).

crease in $S_{R}$. To investigate the robustness of the maximum in $S_{\mathrm{R}}$ in the third LWP bin, we explore the sensitivity of the $5 \mathrm{~km}$ averaged LWP data to the number of bins (Fig. 8). Since the number of data points used for each susceptibility estimate decreases as the number of bins is increased, we use lighter shading for estimates with more bins. The susceptibility generally decreases with increasing LWP, but there is a recognizable dip in susceptibility at $50 \mathrm{~g} \mathrm{~m}^{-2}$. The dip in susceptibility at $50 \mathrm{~g} \mathrm{~m}^{-2}$ appears to be what causes the second LWP bin to have a low susceptibility value, resulting in the susceptibility maximum in the third LWP bin when the data is binned into four bins. Since we have no prior reason to expect a dip in susceptibility at $50 \mathrm{~g} \mathrm{~m}^{-2}$, we expect this dip to not be due to a change in microphysical processes (indeed, the large sampling errors are suggestive of statistical frailty in this result), but further studies with other datasets are necessary to establish whether this dip has a physical explanation.

\subsection{Susceptibility with integrated cloud thickness data}

One of the main points of this paper is to stress the importance of including all clouds when estimating the precipitation susceptibility. Using the Wyoming Cloud Lidar (WCL) and the Wyoming Cloud Radar (WCR) retrievals, we are only able to retrieve cloud thickness measurements for $51 \%$ of the clouds. Thus, our susceptibility estimates are based on those $51 \%$ of the clouds. When we use the LWP data, we calculate the precipitation susceptibility estimates based on $69 \%$ of the clouds. If we combine the LWP and the cloud thickness, we would expect to incorporate a larger fraction of clouds to calculate the precipitation susceptibility. We, therefore, supplement the WCR and WCL-derived cloud thickness measurements with LWP-derived cloud thickness estimates to create an integrated cloud thickness dataset. When 


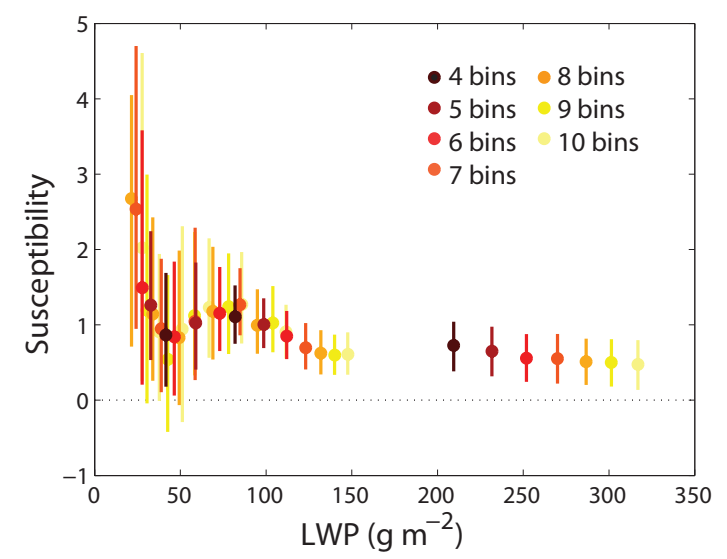

Fig. 8. The precipitation susceptibility is calculated in equally weighted cloud liquid water path (LWP) bins when the data are averaged over $5 \mathrm{~km}$ segments. Different shades denote the number of bins.

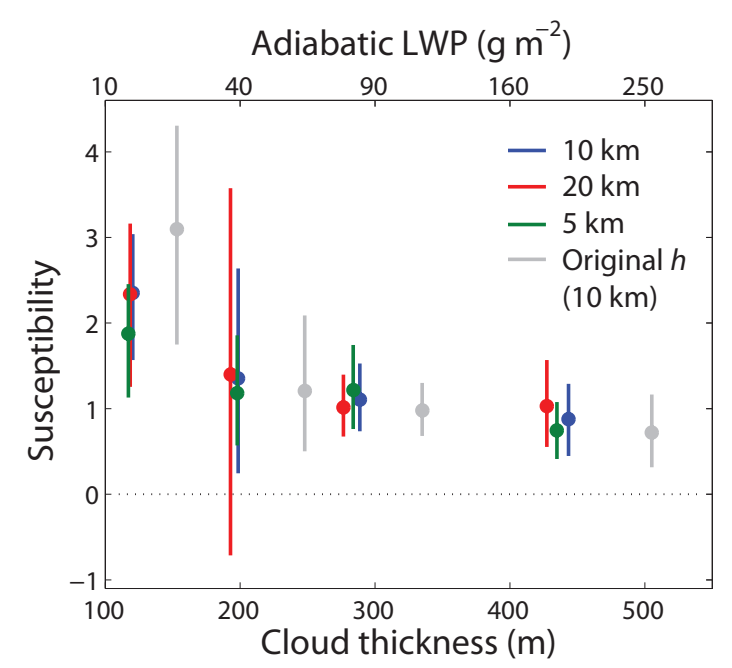

Fig. 9. After combining LWP retrievals from the GVR and the cloud thickness measurements from the WCL and WCR into an integrated cloud thickness dataset, the precipitation susceptibility are calculated in four equally weighted cloud thickness bins for three different averaging length scales: $10 \mathrm{~km}$ (blue), $20 \mathrm{~km}$ (red), $5 \mathrm{~km}$ (green). The original precipitation susceptibility using cloud thickness measurements derived from the WCL/WCR is shown in gray for comparison.

both cloud thickness and LWP measurements are available, the cloud thickness measurements from the WCR and WCL are used.

To convert the LWP retrievals into cloud thickness values we must assume that the cloud liquid water profiles follow the moist adiabat. This assumption is typically valid in marine stratocumulus (Albrecht et al., 1990; Zuidema et al., 2005,2012 ), and the approximation is especially good for the thinner, non-precipitating clouds for which the WCR is unable to detect a cloud top height (Zuidema et al., 2005). We estimate the cloud thickness $h$ values from the cloud LWP values using the expression

$h=\left(\frac{2 \times \mathrm{LWP}}{C_{w}}\right)^{\frac{1}{2}}$,

where $C_{\mathrm{w}}$ is a weak function of temperature and pressure, here $C_{\mathrm{w}}=2 \times 10^{-6} \mathrm{~kg} \mathrm{~m}^{-4}$ (Pawlowska and Brenguier, 2003). With the combined cloud thickness measurements, we can estimate cloud thickness values for $75 \%$ of all clouds detected by the WCL. When we calculate the susceptibility for averaging lengths of 10,20 , and $5 \mathrm{~km}$, and plot it alongside the previous estimates, as in Fig. 9, we note that in general, the mean susceptibility values are similar to those calculated using the cloud thickness measurements from just the WCL and WCR. The uncertainty in the susceptibility estimates, however, substantially increases in the second $h$ bin for this dataset, when compared to the susceptibility estimates in Fig. 6. This demonstrates the difficulty in constraining the susceptibility values using observations. Nonetheless, our overall conclusion that the susceptibility decreases with increasing cloud thickness still holds.

\section{Discussion and conclusions}

We find that the precipitation susceptibility in marine stratocumulus clouds decreases with increasing cloud thickness. The susceptibility of the mean precipitation rate at cloud base is found to decrease by approximately a factor of two to four from the thinnest to the thickest clouds. Because precipitation rate increases strongly with cloud thickness, this result is particularly pertinent to our understanding of aerosol indirect effects. It confirms the findings from both satellite data and simple heuristic models (Kubar et al., 2009; Wood et al., 2009) showing that the ability of aerosols to suppress precipitation is stronger in clouds that produce only weak precipitation. The decrease of $S_{\mathrm{f}}$ with increasing cloud thickness is also consistent with results from L'Ecuyer et al. (2009), namely Fig. $3 b$ that shows larger fractional changes in the probability of precipitation due to changes in aerosol concentrations at lower cloud LWP. On the other hand, it is important to note that with the exception of a couple cases, the precipitation susceptibility $S_{\mathrm{R}}$, as derived in this study, is significantly positive even in the quartile with the thickest clouds. Since the clouds in our dataset span the range of cloud thicknesses typically found in marine stratocumulus, this perhaps indicates a role for aerosols to suppress precipitation in most marine stratocumulus, albeit to a degree that weakens considerably for the thickest clouds.

This result is qualitatively consistent with an analysis of satellite data (Fig. 12 from Kubar et al., 2009), which found that the frequency of drizzle decreases dramatically with a decrease in effective cloud droplet number concentration for clouds with low liquid water path, while there is less of 
a decrease in the frequency for clouds with higher liquid water path. In their study of precipitating cumulus clouds, Sorooshian et al. (2009) found little change in susceptibility at liquid water paths comparable to the liquid water path of the stratocumulus in our study. We attribute the difference to whether or not non-precipitating clouds are included in calculating the susceptibility, though another explanation for the difference may be that the precipitation susceptibility behaves differently with cloud LWP in different thermodynamic environments and cloud regimes. When we repeat our analysis, but remove all of the segments with mean drizzle rates less than $0.01 \mathrm{~mm} \mathrm{day}^{-1}$, we find that there is little change in the susceptibility with increasing cloud thickness. This difference in behavior is related to results from Jiang et al. (2010) and Duong et al. (2011) that found that susceptibility values are sensitive to the minimum threshold for precipitation. The precipitation susceptibility estimates in this study are generally higher than previous airborne studies of marine stratocumulus clouds, such as those of Lu et al. (2009). In their study, they found susceptibility estimates of 0.46 from MASE I and 0.63 from MASE II, based on their separately measured sensitivities of precipitation to cloud droplet number concentration and of cloud droplet number concentration to aerosol concentration.

Another key finding in this study is that the decrease in $S_{R}$ with increasing cloud thickness is due to a decrease in the susceptibility $S_{\mathrm{f}}$ of drizzle fraction rather than the susceptibility $S_{\mathrm{I}}$ of intensity. In other words, $S_{\mathrm{R}}$ decreases, because for thicker clouds aerosol concentrations have a smaller impact on whether clouds drizzle. However, since the $S_{\mathrm{I}}$ is positive in all cloud thickness bins, $S_{\mathrm{R}}$ remains positive even for the thickest of clouds. Regardless of cloud thickness, increasing aerosol concentrations has the same effect in decreasing the relative intensity of drizzle. Sensitivity tests show that although the averaging lengths used to calculate average drizzle rates change the absolute values of the susceptibility, they do not systematically change the response of the susceptibility with cloud thickness.

The method by which we calculate the susceptibility (Eq. 4) is different from previous studies that only incorporate precipitating clouds. One concern with our method would be that we are incorporating clouds with $R=0$ in calculating a metric that takes the logarithm of $R$; the logarithm of zero is undefined. However, as long as there are precipitating clouds in the high $N$ range, the susceptibility introduced in this study captures the effect of aerosols in changing the mean precipitation rate of clouds of a given thickness in the framework of the precipitation susceptibility. We provide a detailed analysis of the method that we use and its limitations in Appendix A. We find that susceptibility estimates from Eq. (4) are sensitive to the number of non-precipitating clouds that are used to calculate the susceptibility. We also find that confidence intervals of susceptibilities calculated using Eq. (4) span the true value of the susceptibility, while those from other methods do not (see Fig. A4).
For much of this study, we have worked under the simple framework for understanding the effect of aerosols on precipitation that follows the model of Eq. (2). The actual dependence of $R$ on $N$ may not be as simple. Regardless of the actual functional dependence of $R$ on $N$, the utility of the $S_{\mathrm{R}}$, we find, is in how it distinguishes the effect that aerosol concentrations have on the intensity of precipitation and the effect that they have on the fraction of precipitation.

Care must be taken, however, if we consider the absolute suppression of precipitation in stratocumulus, since the precipitation susceptibility quantifies only the fractional change in precipitation due to a change in aerosols. Although higher susceptibilities are reported at lower cloud thicknesses, more precipitation is not necessarily suppressed by aerosols at the lower cloud thicknesses. The mean precipitation rate at cloud base of the quartile with thinnest clouds and the quartile with thickest clouds are $0.04 \mathrm{~mm} \mathrm{day}^{-1}$ and $3.69 \mathrm{~mm} \mathrm{day}^{-1}$ respectively. A factor of four decrease of the susceptibility is actually quite small compared to the more than ninety fold increase in mean precipitation rate.

It should also be noted that while this analysis may encompass the range of cloud thicknesses commonly observed in marine stratocumulus, it has only explored a particular subspace of cloud thicknesses and aerosol concentrations occurring in other marine boundary layer clouds. In particular, these results do not inform us about deeper marine boundary layer clouds such as precipitating trade wind cumuli, nor do they help with clouds that are substantially more polluted than the drizzling clouds observed over the southeast Pacific. As noted earlier, this study also excludes more than $20 \%$ of the thinnest clouds for which cloud liquid water path or cloud thickness estimates could not be obtained. Satellite observations from Kubar et al. (2009) also imply that the precipitation susceptibility is a function not only of cloud thickness, but also of the aerosol concentration. Exploring these relationships across different datasets in future studies will help us further constrain the effect of aerosols on precipitation susceptibility.

Finally, we stress that the precipitation susceptibility construct is a correlative rather than a causal one. Establishing the causal nature of the observed susceptibilities is critical for their credibility as evidence of aerosol influence on precipitation. Model results such as those by Feingold and Siebert (2009), Sorooshian et al. (2009), and Wood et al. (2009) are helping to do just that, but there remain significant differences in the magnitudes of the precipitation susceptibilities found in these studies. Further, there are still major gaps in our understanding about what these measurements are telling us about how precipitation susceptibility changes with cloud macrophysical properties. Most notably, studies of relatively thick cumulus clouds (liquid water paths greater than $500 \mathrm{~g} \mathrm{~m}^{-2}$ ) such as those by Sorooshian et al. (2009) and Jiang et al. (2010) show increases in susceptibility, while this study of much thinner stratocumulus clouds appears to show a monotonic decrease. For thinner clouds, the reduction 
in precipitation susceptibility with increasing cloud thickness can be understood as a transition from autoconversiondominated precipitation to accretion-dominated precipitation (Wood et al., 2009). As Jiang et al. (2010) point out, liquid water path is a useful proxy for the ratio of accretion $A_{\text {acc }}$ to autoconversion $A_{\text {auto }}$. However, while the results here support the theoretical arguments of Wood et al. (2009) implying that precipitation susceptibility should decrease monotonically with $A_{\text {acc }} / A_{\text {auto }}$, the cloud resolving model results by Jiang et al. (2010) show a maximum in susceptibility at intermediate values of $A_{\text {acc }} / A_{\text {auto }}$ suggesting that this ratio is not a unique predictor of precipitation susceptibility and that other factors, such as thermodynamic environment and cloud type, may play a role. Seifert and Stevens (2010) suggest that the cloud lifetime (i.e., the time allowed for precipitation to develop) may be one such factor, but we leave this to future studies.

\section{Appendix A}

\section{Tercile log-differencing}

We use the tercile log-differencing (TLD) method to calculate the precipitation susceptibility in this study so that non-precipitating clouds can be included in an analysis that tries to quantify the effect of aerosols on precipitation suppression. Since none of the methods that calculate the susceptibility using regression in log-space incorporate nonprecipitating clouds, they neglect the cases where increased aerosols completely suppress precipitation. In this section, we take a critical look at the TLD method and explore how data distribution, noise, and thresholds can affect the susceptibilities obtained by TLD.

To test how accurately the TLD method estimates a given underlying dependence of precipitation on aerosol concentration, we create multiple synthetic sample datasets with the relationship $R=a N^{-\beta}$ and use each of these to estimate $\beta$. The synthetic model may not exactly capture the true physical dependence of precipitation on aerosol concentration. However, it is desirable that an analysis method can accurately estimate the value of $\beta$. In addition to using TLD, we estimate $\beta$ using a standard least-squares regression in logspace and a linear regression fit in log-space based on minimizing the perpendicular distance between the fit and the data, as discussed by (Reed, 1992). Each data point is equally weighted in all cases.

\section{A1 Distribution of the data}

Many variables in the atmosphere are distributed normally; many are not. Depending on the spatial and temporal extent of the dataset, $N$, our controlling (independent) variable, can in principle be distributed in a number of ways. We find that

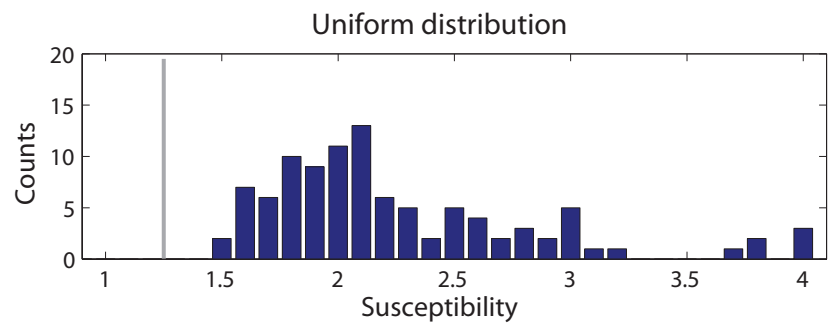

Normal distribution

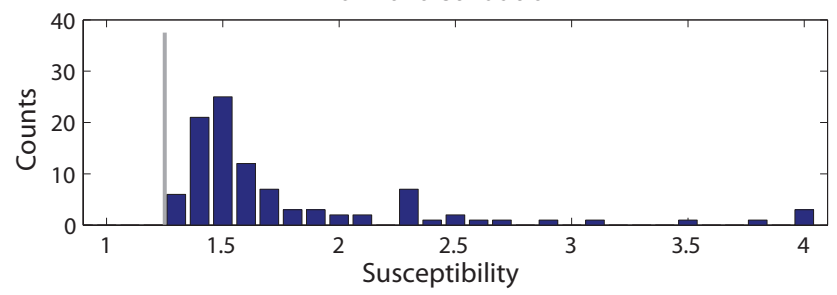

Lognormal distribution

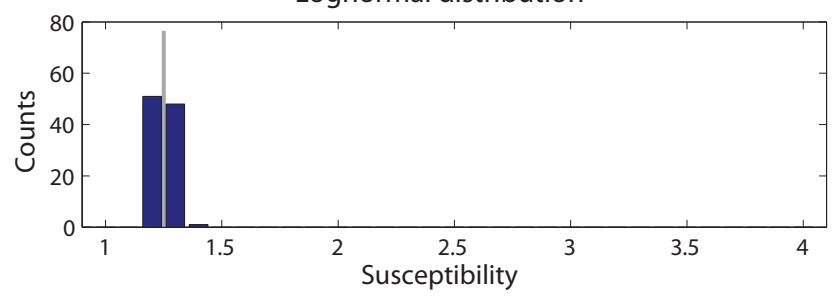

Fig. A1. Histogram of susceptibility estimates using TLD for three different distributions of data: uniform (top), normal (middle), and lognormal (bottom). The histograms are based on 100 estimates calculated from 100 different samples of the same underlying distribution. The gray line at 1.25 shows the value of $\beta$ in the underlying relationship $R=a N^{-\beta}$.

the nature of this distribution has an important impact upon how effective TLD is in estimating $\beta$.

To study this we create a sample dataset of 100 random $N$ values, where $N$ is distributed uniformly, normally, or lognormally. A sample size of 100 is chosen, because the sample size in each of the cloud thickness bins in the VOCALS data is approximately 100 . Corresponding $R$ values are calculated using the relationship $R=a N^{-\beta}$, where $\beta=1.25$; this lies between the mean susceptibility that we estimate for the VOCALS data and the susceptibilities estimated in previous studies. We set $a=50^{1.25}$, but the results for this particular analysis are insensitive to the choice of $a$. To generate a distribution of susceptibility estimates from the three methods (TLD, linear regression, and minimum distance), we resample the set 100 times from the same underlying distribution and calculate the susceptibility in each case, giving us 100 susceptibility estimates. When $N$ is distributed either uniformly or normally, the susceptibilities from TLD overestimate $\beta$, as can be seen in Fig. A1. In these cases, the concentration of points in log-scale is skewed towards higher $N$, resulting in the overestimate of $\beta$. When $N$ is distributed lognormally, the concentration of points is not skewed in logspace, and the value of $\beta$ is more accurately captured by the 

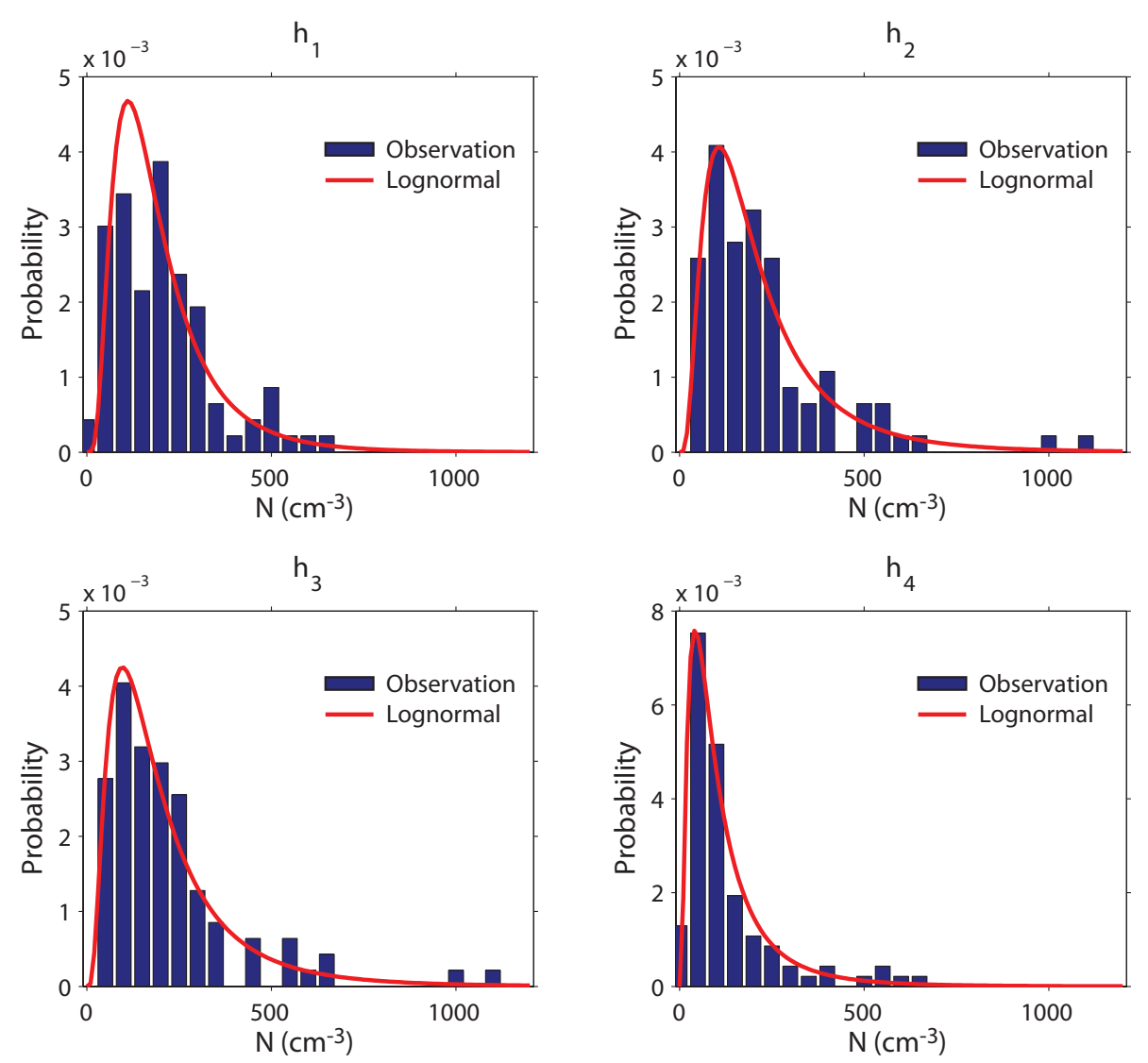

Fig. A2. Histogram of $10 \mathrm{~km}$-averaged PCASP aerosol concentrations $N$ that are used in the susceptibility analysis. Each panel shows the distribution of $N$ in the four cloud thickness bins. The red line shows the probability density function of a theoretical lognormal distribution, based on the arithmetic mean and standard deviation of $N$ in each of the bins.

susceptibility. In this case, we note that the susceptibilities from the linear regression and minimum distance methods accurately capture $\beta$ as one would expect for a dependence of $R$ on $N$ that is simply a power law unburdened with noise that is introduced by both measurement uncertainties and additional controlling variables.

Importantly, the $10 \mathrm{~km}$-averaged PCASP aerosol concentration $N$ (the primary independent aerosol variable used in this study) for each of the four cloud thickness bins $\left(h_{1}\right.$, $h_{2}, h_{3}$, and $\left.h_{4}\right)$ is distributed approximately lognormally (Fig. A2). Neither a uniform nor a normal distribution describes the data well. This gives us confidence that the susceptibility from the TLD method is not likely to be a strongly biased estimator of $\beta$ for our observed data.

\section{A2 Noise level}

In reality, we rarely expect observational data to perfectly fit a model relationship. Instead, we expect there to be noise in the data, representing measurement uncertainties and additional unknown controlling variables. To study the impact of noise on the different methods for estimating $\beta$, we take 100 random samples of $N$, taken from a lognormal distribution with an arithmetic mean of 150 and standard deviation of 75 and calculate $R$ as before. The standard deviation of $R$ before adding the noise is typically 0.22 . To the $R$ value we then add noise taken from a normal distribution with a mean of zero

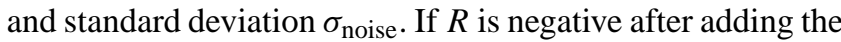
noise, then $R$ is set to zero, since $R$ represents a precipitation rate. We then calculate the susceptibility using the three methods as above, and repeat the process 100 times to obtain a distribution of susceptibilities for each method and for four different noise levels ( $\sigma_{\text {noise }}=0.02,0.1,0.2$, and 0.3 ).

The sensitivity to noise (Fig. A3) shows that all three methods accurately estimate the underlying $\beta$ value for low noise, but as $\sigma_{\text {noise }}$ increases, the minimum distance method increasingly overestimates the $\beta$ value, while both TLD and the standard linear regression method capture the underlying $\beta$ value with minimal bias. The standard linear regression most likely outperforms the minimum distance method, because noise is only added to $R$, and one of the main assumptions of the standard linear regression is that errors in $N$ are zero or negligible. The minimum distance method assumes that errors exist in both $R$ and $N$. We have not carried out a test where we add noise to $N$. 


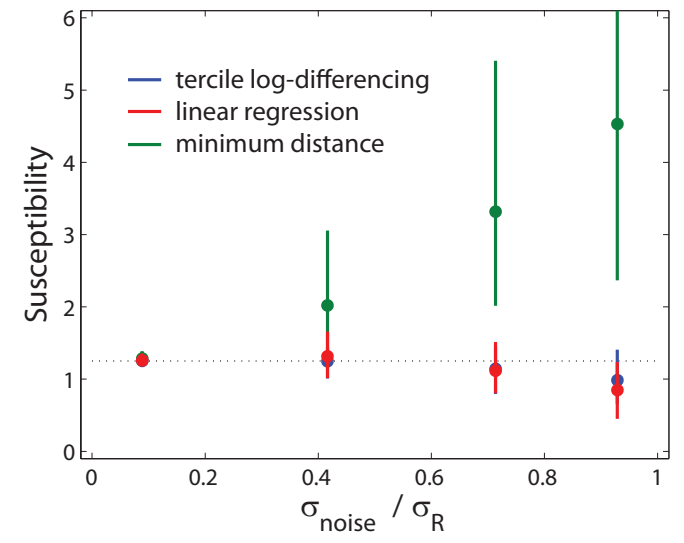

Fig. A3. Susceptibility estimates from TLD (blue), linear regression (red), and minimum distance (green) with increasing noise level. Dots represent mean susceptibilities based on 100 estimates, and the lines show middle $95 \%$ interval. The abscissa shows the ratio between the standard deviation of the distribution from which the noise is taken, $\sigma_{\text {noise }}$, and the standard deviation of $R, \sigma_{\mathrm{R}}$, after the noise has been added. The dotted line represents the underlying $\beta$ value.

\section{A3 Threshold}

Previous studies of precipitation susceptibility have imposed different threshold precipitation rates to differentiate precipitating and non-precipitating clouds. Some of the differences are due to instrument sensitivities, others due to the authors' choices. In this study, we choose the $-15 \mathrm{dBZ}$ threshold, because precipitation rates above $0.14 \mathrm{~mm} \mathrm{day}^{-1}$ (the corresponding precipitation rate) begin to have substantial effects $\left(>4 \mathrm{~W} \mathrm{~m}^{-2}\right)$ on the energetics of the boundary layer.

We test how accurately the three estimators are able to capture $\beta$ when we apply a minimum threshold to $R$. We use the same underlying lognormal distribution as in the previous test to obtain 100 random samples of $N$, and the same relationship between $R$ and $N$. We maintain the noise level at $\sigma_{\text {noise }}=0.3$ and vary the minimum threshold of $R$ such that values of $R$ less than the threshold are set to zero. We choose $\sigma_{\text {noise }}=0.3$, because this gives a $\sigma_{\text {noise-to- } \sigma_{R}}$ ratio that is similar to those found in the VOCALS observations. The mean value of $R$ following the addition of noise, but before the threshold is applied, is typically 0.37 . The four threshold $R$ values we use are $0.01,0.2,0.4$, and 0.6.

Susceptibility estimates from all three methods (Fig. A4) are sensitive to the threshold value. The linear regression method increasingly underestimates the underlying $\beta$ value as the threshold increases. This result is consistent with that of Jiang et al. (2010) and Duong et al. (2011), who both found that increasing the minimum threshold for precipitation decreased the susceptibility estimate. Though the minimum distance method overestimates $\beta$ when the threshold is near zero, it also follows the same trend of decreasing susceptibility estimates with increasing threshold value. The

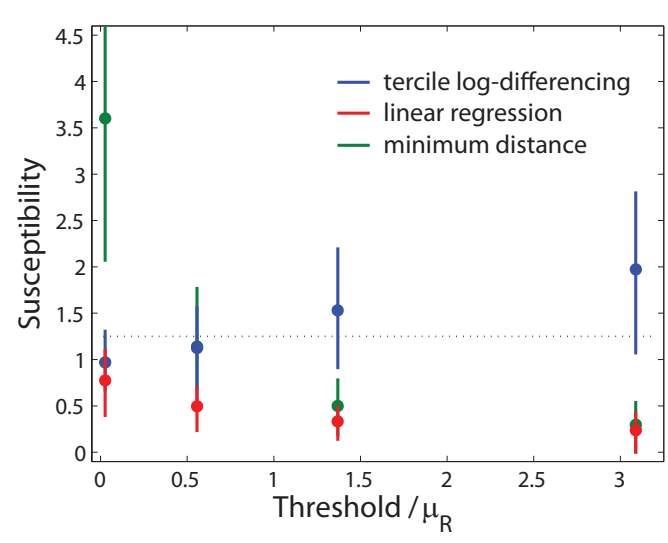

Fig. A4. Susceptibility estimates from TLD (blue), linear regression (red), and minimum distance (green) with increasing threshold level. Dots represent mean susceptibility from 100 estimates and the lines show middle $95 \%$ interval. The abscissa shows the ratio between the threshold value and the mean, $\mu_{\mathrm{R}}$, of $R$ after applying the threshold. The dotted line represents the underlying $\beta$ value.

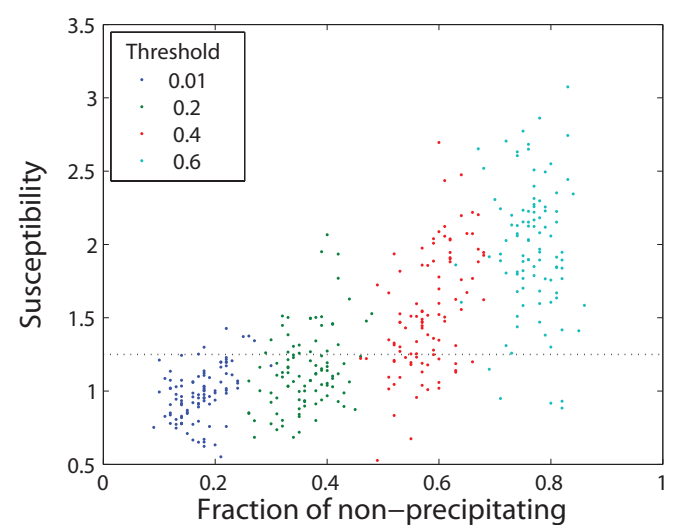

Fig. A5. Susceptibility estimates from TLD as a function of the number of non-precipitating points that went into calculating the susceptibility. Colors indicate different levels of the thresholds: 0.01 (blue), 0.2 (green), 0.4 (red), and 0.6 (cyan). The dotted line represents the underlying $\beta$ value.

TLD, on the other hand, overestimates $\beta$ with increasing threshold value. The susceptibility estimate positively correlates with the fraction of non-precipitating points in each set (Fig. A5). In general, higher susceptibility values are found with increasing fraction of non-precipitating points. From this analysis alone, however, we cannot determine what nonprecipitating fraction would always give an unbiased estimate of $\beta$.

If we split the susceptibility $S_{\mathrm{R}}$ of the TLD method into $S_{\mathrm{f}}$ and $S_{\mathrm{I}}$, as done in the body of the manuscript, we find that $S_{\mathrm{f}}$ increases with increasing fraction of non-precipitating points and provides the vast majority of the trend in $S_{R}$ (Fig. A6). On the other hand, $S_{\mathrm{I}}$ decreases with increasing fraction of non-precipitating points, much like the standard linear regression in Fig. A4. No method consistently gives 


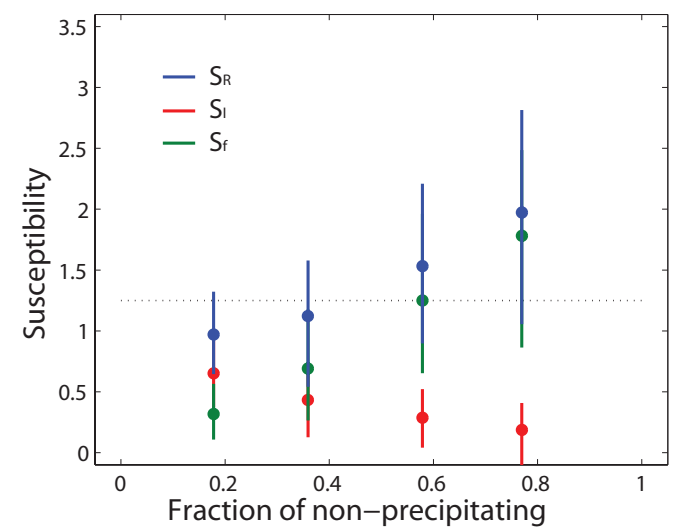

Fig. A6. The precipitation susceptibility $S_{\mathrm{R}}$ (blue), susceptibility of drizzle intensity $S_{\mathrm{I}}$ (red), and susceptibility of drizzle fraction $S_{\mathrm{f}}$ (green) with increasing threshold value, calculated using the TLD method. Instead of the ratio between the threshold and mean precipitation rate, the average fraction of non-precipitating points at each threshold is used for the abscissa. The dotted line represents the underlying $\beta$ value.

an unbiased estimate of the underlying $\beta$ in cases where a substantial number of data values are determined to be nonprecipitating.

\section{A4 Discussion}

We now attempt to put the data from VOCALS REx in context of the above analyses. We can see from Fig. A5 and A6 that susceptibility estimates from TLD increase with the fraction of non-precipitating points. Examining the fraction of non-precipitating clouds will give us an indication of the effect of the threshold on our susceptibility results. The fraction of non-precipitating segments is $0.85,0.46,0.14$, and 0.04 in the four cloud thickness bins of the $10 \mathrm{~km}$-averaged VOCALS data $\left(h_{1}\right.$ to $\left.h_{4}\right)$.

Estimating the "noise" in the data is more difficult. To obtain some estimate of the noise level in the data, we can take the mean susceptibility values that we obtain in each cloud thickness bin and estimate the noise as the difference between the actual $R$ and the $R$ explained by the susceptibility. This crude estimate of the noise gives us $\sigma_{\text {noise-to- } \sigma_{R}}$ ratios of $0.93,0.91,0.72$, and 0.95 in the four cloud thickness bins $\left(h_{1}\right.$ to $\left.h_{4}\right)$. This is not surprising, given that the magnitude of the correlations between $N$ and $R$ are relatively modest in each of the bins: $-0.22,-0.28,-0.42$, and $-0.26\left(h_{1}\right.$ to $\left.h_{4}\right)$.

We conclude that both threshold and noise play an important role in our dataset. The precipitation variations within each cloud thickness bin are dominated by noise, unexplained by the concentration of aerosol concentrations alone. In such cases, linear regression underestimates the $\beta$ value. Figures A5 and A6 show that whether TLD method accurately estimates the $\beta$ value is dependent on the threshold. We also note that Fig. A6 and Fig. 3 are mirror-images of each other, where the difference between the two is that the mean $R$ increases along the abscissa in Fig. 3 and the threshold increases along the abscissa in Fig. A6. $S_{\mathrm{R}}$ increases with the increasing fraction of non-precipitating points. $S_{\mathrm{f}}$, in both cases, determines the trend of $S_{\mathrm{R}}$. $S_{\mathrm{I}}$, on the other hand, display different behaviors in the two figures. $S_{\mathrm{I}}$ in Fig. A6 distinctly increases with decreasing fraction of nonprecipitating points; $S_{\mathrm{I}}$ in Fig. 3 does not display such a clear increase. This suggests that the mechanism causing the behavior of the susceptibility in Fig. 3 is not quite identical to that in Fig. A6, though a large part may be due to it.

From the above analysis alone, we cannot disregard the possibility that in Fig. 3, the underlying dependence between aerosols and precipitation is constant and the decreasing trend of the susceptibility is solely because the fraction of non-precipitating clouds is decreasing. Whereas none of the three methods above always give an unbiased estimate of $\beta$, the utility of $S_{\mathrm{R}}$, as calculated using TLD, is most evident when $S_{\mathrm{R}}$ is taken as the sum of its parts $S_{\mathrm{f}}$ and $S_{\mathrm{I}}$. It informs us about how both the rate and the frequency of precipitation depend upon aerosol concentration. $S_{\mathrm{I}}$, which is more akin to the susceptibilities reported in previous studies, quantifies the effect of aerosols on how intense a cloud precipitates. $S_{\mathrm{f}}$, on the other hand, is a metric that quantifies the effect of aerosols on the drizzle fraction, which is identical to the probability of precipitation when we include $f=0$. L'Ecuyer et al. (2009) found that higher values of aerosol index, which serves as a proxy for columnar concentration of CCN-sized aerosols (Nakajima et al., 2001), tended to decrease the probability of precipitation. They also found that there is no unique liquid water path threshold above which a cloud can be assumed to be precipitating. This interesting finding runs counter to the idea that there is a threshold cloud liquid water path above which all clouds precipitate. $S_{\mathrm{f}}$ in this study attempts to quantify that same effect of aerosol concentrations on the probability of precipitation from the aircraft data from VOCALS. $S_{\mathrm{R}}$ in this study attempts to combine the effect of aerosol concentrations in determining both the intensity and the probability of precipitation.

Acknowledgements. Funding for this work was provided by NSF (ATM-0745702). The authors thank the scientists, staff, ground-crew and aircrew at the NCAR Research Aviation Facility, and the C-130 scientists who were instrumental in the collection of the data analyzed here. Christopher Bretherton, Robert Houze, and Sandra Yuter provided constructive comments on an earlier version of this manuscript. The authors also thank the reviewers for their insightful reviews that helped to improve the manuscript.

Edited by: G. Feingold

\section{References}

Ackerman, A. S., Kirkpatrick, M. P., Stevens, D. E., and Toon, O. B.: The impact of humidity above stratiform clouds on 
indirect aerosol climate forcing, Nature, 432, 1014-1017, doi:10.1038/nature03174, 2004.

Albrecht, B. A.: Aerosols, cloud microphysics, and fractional cloudiness, Science, 245, 1227-1230, doi:10.1126/science.245.4923.1227, 1989.

Albrecht, B. A., Fairall, C., Thomson, D., White, A., and Snider, J.: Surface-based remote sensing of the observed and the adiabatic liquid water content, Geophys. Res. Lett., 17, 89-92, doi:10.1029/GL017i001p00089, 1990.

Allen, G., Coe, H., Clarke, A., Bretherton, C., Wood, R., Abel, S. J., Barrett, P., Brown, P., George, R., Freitag, S., McNaughton, C., Howell, S., Shank, L., Kapustin, V., Brekhovskikh, V., Kleinman, L., Lee, Y.-N., Springston, S., Toniazzo, T., Krejci, R., Fochesatto, J., Shaw, G., Krecl, P., Brooks, B., McMeeking, G., Bower, K. N., Williams, P. I., Crosier, J., Crawford, I., Connolly, P., Allan, J. D., Covert, D., Bandy, A. R., Russell, L. M., Trembath, J., Bart, M., McQuaid, J. B., Wang, J., and Chand, D.: South East Pacific atmospheric composition and variability sampled along $20^{\circ} \mathrm{S}$ during VOCALS-REx, Atmos. Chem. Phys., 11, 5237-5262, doi:10.5194/acp-11-5237-2011, 2011.

Bretherton, C. S., Uttal, T., Fairall, C. W., Yuter, S., Weller, R., Baumgardner, D., Comstock, K., and Wood, R.: The EPIC 2001 stratocumulus study, B. Am. Meteorl. Soc., 85, 967-977, doi:10.1175/BAMS-85-7-967, 2004.

Bretherton, C. S., Wood, R., George, R. C., Leon, D., Allen, G., and Zheng, X.: Southeast Pacific stratocumulus clouds, precipitation and boundary layer structure sampled along $20^{\circ} \mathrm{S}$ during VOCALS-REx, Atmos. Chem. Phys., 10, 10639-10654, doi:10.5194/acp-10-10639-2010, 2010.

Brost, R. A., Wyngaard, J. C., and Lenschow, D. H.: Marine Stratocumulus Layers. Part II: Turbulence Budgets, J. Atmos. Sci., 39, 818-836, doi:10.1175/15200469(1982)039<0818:MSLPIT>2.0.CO;2, 1982.

Chen, Y.-C., Xue, L., Lebo, Z. J., Wang, H., Rasmussen, R. M., and Seinfeld, J. H.: A comprehensive numerical study of aerosolcloud-precipitation interactions in marine stratocumulus, Atmos. Chem. Phys., 11, 9749-9769, doi:10.5194/acp-11-9749-2011, 2011.

Comstock, K. K., Wood, R., Yuter, S. E., and Bretherton, C. S.: Reflectivity and rain rate in and below drizzling stratocumulus, Q. J. Roy. Meteor. Soc., 130, 2891-2918, doi:10.1256/qj.03.187, 2004.

Comstock, K. K., Bretherton, C. S., and Yuter, S. E.: Mesoscale Variability and Drizzle in Southeast Pacific Stratocumulus, J. Atmos. Sci., 62, 3792-3807, doi:10.1175/JAS3567.1, 2005.

Duong, H. T., Sorooshian, A., and Feingold, G.: Investigating potential biases in observed and modeled metrics of aerosol-cloudprecipitation interactions, Atmos. Chem. Phys., 11, 4027-4037, doi:10.5194/acp-11-4027-2011, 2011.

Efron, B. and Gong, G.: A Leisurely Look at the Bootstrap, the Jackknife, and Cross-Validation, Am. Stat., 37, 36-48, doi:10.2307/2685844, 1983.

Feingold, G. and Siebert, H.: Cloud - Aerosol Interactions from the Micro to the Cloud Scale, from the Strüngmann Forum Report, Clouds in the Perturbed Climate System: Their Relationship to Energy Balance, Atmospheric Dynamics, and Precipitation, edited by: Heintzenberg, J. and Charlson, R. J., MIT Press, ISBN 978-0-262-01287-4, 2009.
Feingold, G., Cotton, W. R., Kreidenweis, S. M., and Davis, J. T.: The impact of giant cloud condensation nuclei on drizzle formation in stratocumulus: Implications for cloud radiative properties, J. Atmos. Sci., 56, 4100-4117, doi:10.1175/15200469(1999)056<4100:TIOGCC > 2.0.CO;2, 1999.

Frisch, A. S., Fairall, C. W., and Snider, J. B.: Measurement of stratus cloud and drizzle parameters in ASTEX with a $\mathrm{K}_{a}$-band Doppler radar and a microwave radiometer, J. Atmos. Sci., 52, 2788-2788, doi:10.1175/15200469(1995)052<2788:MOSCAD>2.0.CO;2, 1995.

Geoffroy, O., Brenguier, J.-L., and Sandu, I.: Relationship between drizzle rate, liquid water path and droplet concentration at the scale of a stratocumulus cloud system, Atmos. Chem. Phys., 8, 4641-4654, doi:10.5194/acp-8-4641-2008, 2008.

George, R. C. and Wood, R.: Subseasonal variability of low cloud radiative properties over the southeast Pacific Ocean, Atmos. Chem. Phys., 10, 4047-4063, doi:10.5194/acp-10-4047-2010, 2010.

Gerber, H. and Frick, G.: Drizzle rates and large sea-salt nuclei in small cumulus, J. Geophys. Res., 114, D09211, doi:10.1029/2011JD016249, 2012.

Hudson, J. G., Jha, V., and Noble, S: Drizzle correlations with giant nuclei, Geophys. Res. Lett., 38, L05808, doi:10.1029/2010GL046207, 2011.

Jiang, H., Feingold, G., and Sorooshian, A.: Effect of Aerosol on the Susceptibility and Efficiency of Precipitation in Warm Trade Cumulus Clouds, J. Atmos. Sci., 67(11), 3525-3540, doi:10.1175/2010JAS3484.1, 2010.

Kubar, T. L., Hartmann, D. L., and Wood, R.: Understanding the Importance of Microphysics and Macrophysics for Warm Rain in Marine Low Clouds. Part I: Satellite Observations, J. Atmos. Sci., 66, 2953-2972, doi:10.1175/2009JAS3071.1, 2009.

Leith, C. E.: The Standard Error of Time-Average Estimates of Climatic Means, J. Appl. Meteorl., 12, 1066-1069, doi:10.1175/1520-0450(1973)012<1066:TSEOTA > 2.0.CO;2, 1973.

L'Ecuyer, T., Berg, W., Haynes, J., Lebsock, M., and Takemura, T.: Global observations of aerosol impacts on precipitation occurrence in warm maritime clouds, J. Geophys. Res., 114, D09211, doi:10.1029/2008JD011273, 2009.

Leon, D. C., Wang, Z., and Liu, D.: Climatology of drizzle in marine boundary layer clouds based on 1 year of data from CloudSat and Cloud-Aerosol Lidar and Infrared Pathfinder Satellite Observations (CALIPSO), J. Geophys. Res., 113, D00A14, doi:10.1029/2008JD009835, 2008.

Lu, M. L.,Sorooshian, A., Jonsson, H. H., Feingold, G., Flagan, R. C., and Seinfeld, J. H.: Marine stratocumulus aerosol-cloud relationships in the MASE-II experiment: Precipitation susceptibility in eastern Pacific marine stratocumulus, J. Geophys. Res., 114, D24203, doi:10.1029/2009JD012774, 2009.

Martin, G., Johnson, D., and Spice, A.: The measurement and parameterization of effective radius of droplets in warm stratocumulus clouds, J. Atmos. Sci., 51, 1823-1842, doi:10.1175/15200469(1994)051<1823:TMAPOE>2.0.CO;2, 1994.

Mauger, G. S. and Norris, J. R.: Meteorological bias in satellite estimates of aerosol-cloud relationships, Geophys. Res. Lett., 34, L16824, doi:10.1029/2007GL029952, 2007.

McComiskey, A. and Feingold, G.: Quantifying error in the radiative forcing of the first aerosol indirect effect, Geophys. Res. 
Lett., 35, L02810, doi:10.1029/2007GL032667, 2008.

Nakajima, T., Higurashi, A., Kawamoto, K., and Penner, J. E.: A possible correlation between satellite-derived cloud and aerosol microphysical parameters, Geophys. Res. Lett., 28, 1171, doi:10.1029/2000GL012186, 2001.

Nicholls, S. and Leighton, J.: An observational study of the structure of stratiform cloud sheets: Part I. Structure, Q. J. Roy. Meteor. Soc., 112, 431-460, doi:10.1002/qj.49711247209, 1986.

Painemal, D. and Zuidema, P.: Microphysical variability in southeast Pacific Stratocumulus clouds: synoptic conditions and radiative response, Atmos. Chem. Phys., 10, 6255-6269, doi:10.5194/acp-10-6255-2010, 2010.

Pawlowska, H. and Brenguier, J.-L.: An observational study of drizzle formation in stratocumulus clouds for general circulation model (GCM) parameterizations, J. Geophys. Res., 108, 8630, doi:10.1029/2002JD002679, 2003.

Ramanathan, V., Crutzen, P. J., Kiehl, J. T., and Rosenfeld, D.: Aerosols, climate, and the hydrological cycle, Science, 294, 2119-24, doi:10.1126/science.1064034, 2001.

Reed, B. C.: Linear least-squares fits with errors in both coordinates. II: Comments on parameter variances, Am. J. Phys., 60, 59-62, doi:10.1119/1.17044, 2001

Rotstayn, L. D. and Liu, Y.: A smaller global estimate of the second indirect aerosol effect, Geophys. Res. Lett., 32, 4-7, doi:10.1029/2004GL021922, 2005.

Savic-Jovcic, V. and Stevens, B.: The structure and mesoscale organization of precipitating stratocumulus, J. Atmos. Sci., 65, 15871605, doi:10.1175/2007JAS2456.1, 2008.

Seifert, A. and Stevens, B.: Microphysical Scaling Relations in a Kinematic Model of Isolated Shallow Cumulus Clouds, J. Atmos. Sci., 67, 1575-1590, doi:10.1175/2009JAS3319.1, 2010.

Seinfeld, J. H. and Pandis, S. N.: Atmospheric Chemistry and Physics - From Air Pollution to Climate Change, John Wiley and Sons, Hoboken, New Jersey, USA, 2006.

Sorooshian, A., Feingold, G., Lebsock, M. D., Jiang, H., and Stephens, G. L.: On the precipitation susceptibility of clouds to aerosol perturbations, Geophys. Res. Lett., 36, L13803, doi:10.1029/2009GL038993, 2009.

Sorooshian, A., Feingold, G., Lebsock, M. D., Jiang, H., and Stephens, G. L.: Deconstructing the precipitation susceptibility construct: Improving methodology for aerosolcloud precipitation studies, J. Geophys. Res., 115, D17201, doi:10.1029/2009JD013426, 2010.

Stevens, B. and Feingold, G.: Untangling aerosol effects on clouds and precipitation in a buffered system, Nature, 461(7264), 60713, doi:10.1038/nature08281, 2009.

Stevens, B., Cotton, W. R., Feingold, G., and Moeng, C.-H.: Large-Eddy Simulations of Strongly Precipitating, Shallow, Stratocumulus-Topped Boundary Layers, J. Atmos. Sci., 55, 3616-3638, doi:10.1175/15200469(1998)055<3616:LESOSP>2.0.CO;2, 1998.

Turton, J. and Nicholls, S.: A study of the diurnal variation of stratocumulus using a multiple mixed layer model, Q. J. Roy. Meteor. Soc., 113, 969-1009, doi:10.1002/qj.49711347712, 1987.

Vali, G., Kelly, R. D., French, J., Haimov, S., Leon, D., McIntosh, R. E., and Pazmany, A.: Finescale Structure and Microphysics of Coastal Stratus, J. Atmos. Sci., 55, 3540-3564, doi:10.1175/1520-0469(1998)055<3540:FSAMOC > 2.0.CO;2, 1998.
vanZanten, M. C., Stevens, B., Vali, G., and Lenschow, D. H.: Observations of drizzle in nocturnal marine stratocumulus, J. Atmos. Sci., 62, 88-106, doi:10.1175/JAS-3355.1, 2005.

Wang, S. and Albrecht, B. A.: A stratocumulus model with an internal circulation, J. Atmos. Sci., 43, 2374-2391, doi:10.1175/1520-0469(1986)043<2374:ASMWAI > 2.0.CO;2, 1986.

Wood, R.: Drizzle in Stratiform Boundary Layer Clouds, Part I: Vertical and Horizontal Structure, J. Atmos. Sci., 62, 3011-3033, doi:10.1175/JAS3529.1, 2005.

Wood, R.: Rate of loss of cloud droplets by coalescence in warm clouds, J. Geophys. Res., 111, D21205, doi:10.1029/2006JD007553, 2006.

Wood, R.: Cancellation of Aerosol Indirect Effects in Marine Stratocumulus through Cloud Thinning, J. Climate, 19, 1748-1764, doi:10.1175/JAS3942.1, 2007.

Wood, R. and Hartmann, D. L.: Spatial Variability of Liquid Water Path in Marine Low Cloud: The Importance of Mesoscale Cellular Convection, J. Climate, 19, 1748-1764, doi:10.1175/JCLI3702.1, 2006.

Wood, R., Kubar, T. L., and Hartmann, D. L.: Understanding the Importance of Microphysics and Macrophysics for Warm Rain in Marine Low Clouds. Part II: Heuristic Models of Rain Formation, J. Atmos. Sci., 66, 2973-2990, doi:10.1175/2009JAS3072.1, 2009.

Wood, R., Bretherton, C. S., Leon, D., Clarke, A. D., Zuidema, P., Allen, G., and Coe, H.: An aircraft case study of the spatial transition from closed to open mesoscale cellular convection over the Southeast Pacific, Atmos. Chem. Phys., 11, 2341-2370, doi:10.5194/acp-11-2341-2011, 2011.

Wood, R., Mechoso, C. R., Bretherton, C. S., Weller, R. A., Huebert, B., Straneo, F., Albrecht, B. A., Coe, H., Allen, G., Vaughan, G., Daum, P., Fairall, C., Chand, D., Gallardo Klenner, L., Garreaud, R., Grados, C., Covert, D. S., Bates, T. S., Krejci, R., Russell, L. M., de Szoeke, S., Brewer, A., Yuter, S. E., Springston, S. R., Chaigneau, A., Toniazzo, T., Minnis, P., Palikonda, R., Abel, S. J., Brown, W. O. J., Williams, S., Fochesatto, J., Brioude, J., and Bower, K. N.: The VAMOS Ocean-Cloud-AtmosphereLand Study Regional Experiment (VOCALS-REx): goals, platforms, and field operations, Atmos. Chem. Phys., 11, 627-654, doi:10.5194/acp-11-627-2011, 2011.

Wyant, M. C., Bretherton, C. S., Chlond, A., Griffin, B. M., Kitagawa, H., Lappen, C.-L., Larson, V. E., Lock, A., Park, S., de Roode, S. R., Uchida, J., Zhao, M., and Ackerman, A. S.: A single-column model intercomparison of a heavily drizzling stratocumulus-topped boundary layer, J. Geophys. Res., 112, D24204, doi:10.1029/2007JD008536, 2007.

Yuter, S., Serra, Y., and Houze Jr., R. A.: The 1997 Pan American climate studies tropical eastern Pacific process study. Part II: Stratocumulus region, B. Am. Meteorl. Soc., 81(3), 483-490, 2000.

Zuidema, P., Westwater, E. R., Fairall, C., and Hazen, D.: Shipbased liquid water path estimates in marine stratocumulus, J. Geophys. Res., 110, D20206, doi:10.1029/2005JD005833, 2005.

Zuidema, P., Leon, D., Pazmany, A., and Cadeddu, M.: Aircraft millimeter-wave passive sensing of cloud liquid water path and water vapor during VOCALS-REx, Atmos. Chem. Phys., 12, 355-369, doi:10.5194/acp-12-355-2012, 2012. 